NBER WORKING PAPER SERIES

\title{
THE ROLE OF SEARCH IN UNIVERSITY PRODUCTIVITY: INSIDE, OUTSIDE, AND INTERDISCIPLINARY DIMENSIONS
}

\author{
James D. Adams \\ J. Roger Clemmons \\ Working Paper 15489 \\ http://www.nber.org/papers/w15489
NATIONAL BUREAU OF ECONOMIC RESEARCH
1050 Massachusetts Avenue
Cambridge, MA 02138
November 2009

The Andrew W. Mellon Foundation generously supported this research. We thank Nancy Bayers and Henry Small of Thomson-Reuters Scientific for advice on the data, the editors for their patience, W. Edward Steinmueller for helpful remarks on interdisciplinary research, and Paula E. Stephan and two referees for comments. Any remaining errors are our responsibility. This paper was presented at a conference on "The Economics and Policy of Academic Research," held at the Collegio Carlo Alberto, Torino, Italy, on July 14-15, 2008; and at the Communia 2009 Conference, also held in Torino on June 28-30, 2009. The views expressed herein are those of the author(s) and do not necessarily reflect the views of the National Bureau of Economic Research.

NBER working papers are circulated for discussion and comment purposes. They have not been peerreviewed or been subject to the review by the NBER Board of Directors that accompanies official NBER publications.

(C) 2009 by James D. Adams and J. Roger Clemmons. All rights reserved. Short sections of text, not to exceed two paragraphs, may be quoted without explicit permission provided that full credit, including (C) notice, is given to the source. 
The Role of Search in University Productivity: Inside, Outside, and Interdisciplinary Dimensions James D. Adams and J. Roger Clemmons

NBER Working Paper No. 15489

November 2009

JEL No. D24,D80,L31,O32,O33,O38

\begin{abstract}
$\underline{\text { ABSTRACT }}$
Due to improving information technology, the growing complexity of research problems, and policies designed to foster interdisciplinary research, the practice of science in the United States has undergone significant structural change. Using a sample of 110 top U.S. universities observed during the late 20th century we find that knowledge flows, both in total and in their major components, are a significant and positive determinant of research output. Outside knowledge-flows from other universities have increased at a faster rate than inside flows from the same university. Over time, the importance of outside flows for research output has risen, and it has done so at a faster rate than the importance of inside flows has decreased. Thus the overall contribution of knowledge-flows has increased and has shifted towards outside flows.

Turning to knowledge-flows by field, we find that interdisciplinary knowledge-flows have increased only slightly relative to same field flows, despite policy initiatives that favor interdisciplinary research. Moreover, the importance of interdisciplinary flows for research output, while positive and statistically highly significant, has stayed about the same, even as same field flows have become more important, probably because of growth in cyber infrastructure. Although a final verdict is yet to be reached, one interpretation is that interdisciplinary research is still in its early stages. While interdisciplinary flows have begun to increase, the resulting discoveries, and their influence on subsequent research, may still lie in the future.
\end{abstract}

James D. Adams

Department of Economics

Rensselaer Polytechnic Institute

3406 Russell Sage Laboratory

Troy, NY 12180-3590

and NBER

adamsj@rpi.edu

J. Roger Clemmons

Institute for Child Health Policy

College of Medicine

The University of Florida

PO Box 100147

Gainesville, FL 32610-0147

jrc@ichp.ufl.edu 


\section{Introduction}

What role does information technology play in the choice between local research, distant research, and research within a field versus between fields? Can science policy bring scientists together from different fields to produce significant hybrid research? And do these synthetic discoveries exert a rising influence on subsequent research? In this paper we explore these questions using a panel of 110 top U.S. universities.

Any such study must come to grips, either informally or formally, with the self-interests of researchers. Scientists search for knowledge that is useful for their own work. That in turn contributes to the pleasure of discovery, to promotion and wage growth, and to the chance of prestigious awards. Taking these goals as given, search is conditioned by characteristics of knowledge that affect its costs and returns. These characteristics include distinctions between the same and other universities and fields. Put differently, search is shaped by inside, outside, and interdisciplinary dimensions of knowledge. The resulting knowledge-flows depend on the costs and returns from search. For example, interdisciplinary flows will be meager if it is more costly to acquire knowledge from other fields. Conversely, the flows will increase if policy creates research centers which encourage joint research by scientists from different fields.

To explore these questions we use a panel of fields, universities, and years, observed during 1981-1999. The data account for most academic research in the U.S., and in combination with a similar panel for firms, they account for most scientific research in the U.S. Using a definition of knowledge-flows equal to citation-weighted Research and Development (R\&D) stocks, we obtain the following findings. First, the share in all knowledge-flows of outside knowledge from other universities increases by $30 \%$. Hence outside flows rise relative to inside flows from the same university. The share of interdisciplinary flows also increases, but the increase is slight, 
about $10 \%$ across fields. The interdisciplinary share rises faster, by $70 \%$, in engineering and mathematics. But the share declines or remains flat in astronomy, computer science, economics and business, medicine, and physics.

Given the rising use of interdisciplinary research in engineering, we undertake a detailed study of citation flows for engineering subfields. We observe a drop in the citation share from the same subfield, a flat share for other engineering, and a rising share for science outside engineering. We undertake a similar study for mathematics and statistics. Pure and applied mathematics increasingly cites physics, while statistics increasingly cites biology and medicine. Since engineering and mathematics are the focal point of U.S. policies favoring interdisciplinary research, it appears that the policies may have had some effect on these disciplines.

Much of the paper explores the role of knowledge-flows on research "output" as measured by papers or citations received. We find that knowledge-flows uniformly increase papers and citations $^{1}$. This applies to all major knowledge-flows, including those from the same university or field and from other universities or fields. Outside knowledge-flows from other universities are more important than inside knowledge-flows from the same university. Moreover, the importance of outside flows has increased at a faster rate than the importance of inside flows has decreased, so that over time knowledge-flows contribute more to research output. Also, knowledge-flows from the same field are more important than knowledge-flows from other fields, though both contribute significantly to scientific discovery. The importance of flows from the same field again increases, with most of this coming from other universities. Turning to interdisciplinary flows, we find that knowledge-flows from other fields and the same university are as important as flows from other fields and other universities. Thus interdisciplinary flows

\footnotetext{
${ }^{1}$ Importance is measured by the output elasticity with respect to each knowledge-flow. In turn the output elasticity is the percent change in research output per one percent change in a flow.
} 
are more localized than same field flows. We also consider knowledge-flows from "hot" interdisciplinary fields, whose share is increasing, separately from "cold” fields, whose share is flat or decreasing. We find that the importance of "hot" fields in production does not rise relative to "cold”, nor are "hot” fields consistently more important than "cold” fields. Interdisciplinary research, while promising, does not assume a larger role in the production of new scientific ideas during this period. Since interdisciplinary flows result from changes in policy and search costs as well as production, their share in knowledge-flows could increase slightly, even though their importance in production remains about the same.

This analysis has several implications. Since knowledge from the same university declines in importance relative to knowledge from other universities, the private incentives of investigators, as conditioned by policy and growth of cyber infrastructure, favor a more outward university system, and that in turn has contributed to productivity. And since interdisciplinary knowledgeflows increase slowly relative to all flows and even decrease in some fields, then despite encouragement from science policy, researchers are voting with their minds against looking outside their discipline for knowledge thought to be instrumental to their success. Even so, in coming years interdisciplinary research may grow in importance. The rising share of interdisciplinary flows in engineering and mathematics could be an early sign of this change.

The rest of the paper is arranged as follows. Section II is a literature review and a review of recent policies towards interdisciplinary research. Section III presents the analytical framework. Data and variable construction take up Section IV, while Section V provides a descriptive overview of the key variables. Section VI consists of regression analysis of the production of scientific papers in universities, with emphasis on interdisciplinary research. Section VII undertakes a brief comparative analysis for firms. Section VIII is a summary and conclusion. 


\section{Review of the Literature A. Conceptual Studies}

The size of teams and the extent of collaboration have risen steadily over the $20^{\text {th }}$ century (Zuckerman and Merton, 1973; De Sola Price, 1986; Hicks and Katz, 1996), with clear implications for citation patterns. Co-location of team workers is less common because of growing cyber infrastructure, and likewise the composition of teams has become more international in scope (Adams, Black, Clemmons and Stephan, 2005). Rosenblat and Mobius (2004) suggest that cyber infrastructure promotes substitution of collaboration within disciplines for collaboration between disciplines.

Interdisciplinary research in particular depends on collaboration to reduce the cost of combining disciplines. Thus Katz and Martin (1997) point out that collaboration is logically connected to specialization within conventional disciplines as well as research teams cutting across disciplines and institutions. The U.S. National Academy of Sciences (Committee on Science, Engineering, and Public Policy, 2004) considers interdisciplinary teams. The report asserts, though it does not prove, that notable advances in science depend on this kind of research. However, it admits that interdisciplinary research imposes high learning costs on team workers, and that it reduces publication rates and the chance of winning tenure. Interdisciplinary teams also impose higher internal communication costs (Jeffries, 2003).

Holton, Chang and Jurkowitz (1996) underscore these considerations in their remarkable case study of high temperature superconductivity. Preconditions at IBM Zurich consisting of high-quality, long term research in many disciplines helped make this discovery possible ${ }^{2}$. But the quality and range of the co-discoverers, Muller and Bednorz, as well as the esthetic sense of

\footnotetext{
${ }^{2}$ For other discoveries that entail a degree of interdisciplinary research, see Nelson (1962) for the transistor and Hounshell and Smith (1988) for nylon and the artificial fibers.
} 
Muller developed over several decades—-these too were essential. So while interdisciplinary research may figure into great discoveries, its costs exceed those of traditional research.

Corley, Boardman, and Bozeman (2006) find that large science projects spanning multiple institutions and disciplines require a high level of development of knowledge and organizational structure to provide rules for the collaboration. Adams, Chiang, and Jensen (2001), and Boardman and Corley (2008) emphasize the role of university research centers for outside research collaboration. Boardman and Corley (2008) find that the centers increase collaboration, but that the structure of the centers matters for the composition of collaboration. For example industry-linked centers encourage joint work with industry that substitutes for joint work with academia. These papers are a sample of research on collaboration.

\section{B. Policy Initiatives of the U.S. National Science Foundation and the U.S. National Institutes of Health}

Recent U.S. policies favor collaborative and interdisciplinary research. The National Science Foundation (NSF), which supports research in universities, promotes this research through its NSF-Wide Investments, of which the NSF Centers are a leading example:

\footnotetext{
Centers exploit opportunities in science, engineering, and technology in which the complexity of the research problem or the resources needed to solve the problem require the advantages of scope, scale, duration, equipment, facilities, and students. Centers are the principal means by which NSF fosters interdisciplinary research. - National Science Foundation (2009b), “NSF Centers and Funding”
}

The programs (founding dates) are: Engineering Research Centers (1985), Science and Technology Centers (1987), Materials Research Science and Engineering Centers (1994), Centers for Analysis and Synthesis (1995), Centers for Chemical Innovation (1998), Nanoscale Science and Engineering Centers (2001), and Science of Learning Centers 
(2003). Weighted by funding shares, the average year of founding is $1992^{3}$. The centers involve high-risk, long-term, but high payoff research. Recognizing this, NSF provides seed money for 8-10 years and one stated purpose of the centers is to educate graduate students for the next generation.

Besides the centers NSF maintains the National Nanotechnology Initiative, whose purpose is to understand and control matter at the atomic, molecular, and supra-molecular levels, and which, as an NSF-wide investment has an interdisciplinary component. New NSF-wide investments are Cyber-Enabled Discovery and Innovation, and Science and Engineering beyond Moore's Law. While U.S. policies towards interdisciplinary research have existed since the 1980s they have clearly gained momentum over time.

Besides engineering programs NSF maintains a program in mathematical biology, under Mathematical Sciences, that is designed to mesh with collaborating biology programs. And the National Institutes of Health (NIH), which also supports universities, operates Bioinformatics Resource Centers (NIH, 2009). These employ multi-disciplinary teams of microbiologists, specialists in bioinformatics, and computer scientists. From this discussion one would expect interdisciplinary citations to increase fastest in engineering and mathematics and statistics. Section $\mathrm{V}$ finds that this is the case.

\section{Knowledge Production Function for Science}

The production of knowledge reflects a series of prior decisions. Among these are choices of whether to carry out search within a discipline or between disciplines, and with which disciplines. It is a question of which approach maximizes the life cycle utility of the scientist. On the one hand, interdisciplinary research requires a more extensive division of labor and coordination costs (Becker and Murphy, 1992). It imposes delays in carrying out research and it

\footnotetext{
${ }^{3}$ In 2007 total funding for the centers was 232.5 million dollars.
} 
entails an increased risk that combinations of diverse ideas will fail. On the other hand, it may offer a better chance of research breakthroughs. Policies that subsidize interdisciplinary research tilt scientists' decisions in its favor. The state preference model (Hirshleifer and Riley, 1992) seems capable of imbedding decisions on choice of productive method that reflect these considerations. While space limitations preclude such modeling here, the choice of research methods clearly depends on comparative costs and returns as well as policy.

In Section VI we estimate a knowledge production function for science using a panel of fields, universities, and years. To create a bridge to the empirical work, in this section we briefly explore the details of this function, which relates new discoveries to physical assets and to knowledge used in research. Production takes place in a university-field, defined as field $i$ and university $j$ at timet. Assume a Cobb-Douglas production function for scientific discoveries:

$$
n_{i j t}=A \exp \left(Z_{D}^{\prime} \delta\right) R_{(i j) t-1}^{\eta_{R}} \prod_{w=1}^{W}\left(S_{(i j) t-1}^{w}\right)^{\eta_{w}} \exp \left(u_{i j t}\right)
$$

The "output" of discoveries $n_{i j t}$ is on the left: it is measured by papers or citations received. On the right is $A$, output not elsewhere accounted for, and $Z_{D}^{\prime}$, a vector of field, university, and time fixed effects multiplied by coefficient vector $\delta^{4}$. We include field fixed effects to absorb differences in research output among disciplines. We use fixed effects for universities to absorb permanent differences in institutional productivity. The university effects are fixed since the universities that we study account for most academic R\&D in the U.S. and are fixed in repeated samples (Hsiao, 2003, Ch. 4). We include year fixed effects to capture secular changes in research output not elsewhere accounted for. The inclusion of the different fixed effects is standard practice in panel data econometrics for the reasons given. The stock of lagged R\&D $R_{(i j) t-1}$ captures tangible assets in a field and university: computers and laboratory equipment,

${ }^{4}$ Fixed effects are dummy variables equal to 1 if something is true and 0 otherwise. 
faculty release time, and student assistants, which accumulate in the course of past projects. In contrast $S_{(i j) t-1}^{w}$ is a vector of lagged intangible knowledge-flows to a university-field from the same and other universities; from the same and other fields; and from the same and other universities and fields. The stock of $\mathrm{R} \& \mathrm{D} R_{(i j) t-1}$ and the knowledge-flows $S_{(i j) t-1}^{w}$ are knowledge inputs that are used to produce research output.

The output elasticities $\eta_{R}$ and $\eta_{w}$ are percentage changes in output per one percent change in the knowledge inputs. They indicate importance in production. Sometimes we let $\eta_{w}$ vary with time to account for factor-biased technical change. In (1) $u_{i j t}$ is the error term

$$
u_{i j t}=v_{i}+v_{j}+v_{t}+e_{i j t}
$$

The $v_{i}, v_{j}, v_{t}$ terms are permanent variance-components for field, university, and time that are absorbed by the fixed effects $Z_{D}^{\prime}$ so that $u_{i j t}=Z_{D}^{\prime} \delta+e_{i j t}$. In (2) $e_{i j t}$ is the "innovation" in the error. If this is uncorrelated over time, then inclusive of $Z_{D}^{\prime} e_{i j t}$ should be uncorrelated with the knowledge inputs. Estimates of the regression coefficients should be unbiased, or identified.

Taking logarithms of (1) and substituting (2) and $u_{i j t}=Z_{D}^{\prime} \delta+e_{i j t}$ into the result we reach:

$$
\ln \left(n_{i j t}\right)=\beta+Z_{D}^{\prime} \delta+\eta_{R} \ln \left(R_{(i j) t-1}\right)+\sum_{w=1}^{W} \eta_{w} \ln \left(S_{(i j) t-1}^{w}\right)+e_{i j t}
$$

Here $\beta$ is the logarithm of $A$ shown in (1). We estimate (3) in Section VI for universities and in Section VII for firms.

\section{Database}

\section{A. Data Sources}

The underlying university data consist of 2.4 million unique scientific papers, published during 1981-1999, that have at least one author from the top 110 U.S. universities. These 
universities account for more than 80 percent of academic R\&D in the U.S. ${ }^{5}$.

Papers consist of articles, reviews, notes, and proceedings. The data source is ThomsonReuters Scientific ${ }^{6}$. Papers are assigned to one of 88 fields according to the field classification of the journal where they appear (see Adams and Clemmons, 2008 for a description). To link the papers data to R\&D expenditures in the National Science Foundation's (NSF) CASPAR database (NSF, 2009a) we assign each of the 88 fields to one of 12 NSF fields: agriculture, astronomy, biology, chemistry, computer science, earth sciences, economics and business, engineering, mathematics and statistics, medicine, physics, and psychology.

The Thomson-Reuters data record publication year, journal field, author names, and address information that includes academic unit titles, as well as city, state and country. Academic unit titles are assigned to universities by means of institutional directories developed by Thomson-Reuters in the course of its construction of the Science and Social Science Citation Indexes. The academic units are a compendium of administrative divisions of a university, nearly all of which are departments or professional schools. Titles appear in addresses that are separate from author names so that names cannot be assigned to universities. For this reason we use academic units and not names to assign papers to universities. Consider a paper in medicine that lists five addresses with five academic unit titles. Three are divisions of the Harvard Medical School and Harvard University. The fourth is part of Yale and the fifth belongs to Johns Hopkins. Given this assignment of academic units to universities, 3/5 of the paper is assigned to Harvard, 1/5 to Yale, and 1/5 to Johns Hopkins. Let us now discuss the assignment of citations

\footnotetext{
${ }^{5}$ National Science Board (2002), Appendix Table 5-4, shows that in 1999 the top 100 U.S. universities account for $\$ 22.10$ billion of R\&D out of $\$ 27.49$ billion of R\&D for all U.S. universities. This equals 80.4 percent. National Science Board (2008), Appendix Table 5-11 indicates that in 2006 the top 100 account for $\$ 38.09$ billion out of $\$ 47.76$ billion for all U.S. universities. This equals 79.8 percent. Since the sample consists of the top 110 and not the top 100 , its share in $R \& D$ expenditures exceeds 80 percent.

${ }^{6}$ The journal set consists of approximately 5500 journals that were active in 1999 as well as 1600 inactive (renamed or discontinued) journals cited by active journals.
} 
received. In the empirical work we use citations from the year of publication through the next four years. We take out institutional self-citations. Then, to assign citations received by an institution, we multiply the remaining citations received by the fraction of academic units that belong to each university. In the example, suppose that Harvard receives 29 citations from other universities, Yale receives 31; and Johns Hopkins 30. In this example we assign $3 / 5 \times 29=17.4$ fractional citations to Harvard, $1 / 5 \times 31=6.2$ to Yale, and $1 / 5 \times 30=6$ to Johns Hopkins.

To construct the dependent variables we aggregate fractional papers and citations to the level of fields, universities, and years. This yields observable measures of "outputs" of new scientific discoveries in a university-field. We use lagged, deflated R\&D expenditures in a university-field to construct stocks of R\&D over the previous eight years. For 1985 papers and citations, say, we construct R\&D stocks based on R\&D expenditures from 1978 to 1984 . The NSF CASPAR database of universities (NSF, 2009a) provides the university R\&D data. R\&D consists of all research funding, both external and internal. About 75 percent of university R\&D consists of basic research, 22 percent consists of applied research, and four percent consists of development (National Science Board, 2008, Chapter 5).

To create the knowledge-flows, we construct citations made by a field, university and year to any field, university, and year and the number of papers that could have been cited. Since the sample consists of the top 110 U.S. universities, citations occur among this set of schools. The ratio of citations to papers potentially cited is a citation rate. We multiply this rate by the stock of R\&D in the cited field, university and year, where the R\&D stock proxies for stocks of knowledge produced. Then we sum the citation rates times cited R\&D stocks for each citing field, university, and year. This yields the knowledge-flows used in this paper. 
In building the panel we consider only highly ranked departments, plus a remainder that aggregates the rest, so that we retain all the data. Our reason for constructing the remainder is to avoid empty cells where fields are small or non-existent ${ }^{7}$. To capture quality of research program we rely on rankings of doctoral programs. National Research Council’s 1993 Survey of Doctoral Programs (NRC, 1995) is the source of these rankings. We include a larger number of ranked departments in larger fields since more of the programs are ranked. In fact we include the top 25 universities in astronomy, the top 50 in agriculture, chemistry, computer science, economics and business, earth sciences, mathematics and statistics, physics, and psychology; and the top 75 in biology, medicine, and engineering. Summing across fields and noting that 48 formal schools of agriculture exist, the panel consists of 648 university-fields in a given year. Adding the 12 remainders, one for each discipline, we arrive at 660 university-fields.

Although the data begin in 1981, backward references to scientific literature require at least one lag, costing 1981, and a further lag of one year for the knowledge inputs costs 1982. Thus the panel begins in 1983. It contains papers and citations received, lagged R\&D stocks, and lagged knowledge-flows for 660 university-fields in 12 sciences during 1983-1999. This implies 11,220 observations before exclusions due to missing values.

\section{B. Specification of the Variables}

Knowledge-flows are sums of cited R\&D stocks multiplied by citation rates that represent sampling rates ${ }^{8}$. We justify this by noting that the R\&D stocks are correlated with unobservable stocks of knowledge, so the product of the stocks and the citation rates yields a measure of the proportion of knowledge that leaks out to a citing university-field ${ }^{9}$.

\footnotetext{
${ }^{7}$ The remainder equals an average university-field in individual ranked departments. This reflects the positive skew of academic R\&D. For more on this see Adams and Griliches (1998).

${ }^{8}$ For papers relating search to technological change see Nelson (1982) and Kortum (1997).
} 
To express this in algebra note that the citation rate equals $\mathrm{c}_{i j t}^{F k \tau} / n_{F k \tau}$. The numerator $\mathrm{c}_{i j t}^{F k \tau}$ equals citations made by citing field $i$ in university $j$ in year $t$ to cited field $F$ in university $k$ in prior year $\tau(\tau<t)$. It represents search effort ${ }^{10}$. Citations are divided by $n_{F k \tau}$, the count of scientific papers in the cited field, university, and year. The resulting citation rate measures the intensity with which researchers draw on knowledge stocks elsewhere. For a group of citing papers $n_{i j t}$ the citation ratec $c_{i j t}^{F k \tau} / n_{F k \tau}$ is preferable to the citation probability $\mathrm{c}_{i j t}^{F k \tau} / n_{i j t} n_{F k \tau}$. For a single paper, the citation probability captures the proportion of knowledge flowing from cited to citing groups (Adams, Clemmons, and Stephan, forthcoming 2006). But if $n_{i j t}$ papers cite $n_{F k \tau}$ papers, then the probability $C_{i j t}^{F k \tau} / n_{i j t} n_{F k \tau}$ times $n_{i j t}$ equals the citation rate $c_{i j t}^{F k \tau} / n_{F k \tau}$. This measures the proportion of knowledge in the cited group that reaches a group of citing papers.

Citations made to the same citing university are inside citations; those made to other universities are outside citations. Citations made within a science are same field citations, while citations outside a science are interdisciplinary in nature.

The flow of inside knowledge from the same university is

$$
S_{i j t}^{\text {Same University }}=\sum_{F=1}^{M} \sum_{\tau=1}^{t-1}\left(c_{i j t}^{F j \tau} / n_{F j \tau}\right) \mathrm{R}_{F j \tau}
$$

It is the sum over all fields, previous years, and the same university, of citation rates multiplied by R\&D stocks. In (4) the stock of university and field R\&D is

$$
R_{F j \tau}=\sum_{z=1}^{8} r_{(F j) \tau-z}(1-d)^{z}
$$

\footnotetext{
${ }^{9}$ For a paper that demonstrates equivalence between the stock of $R \& D$ and the stock of knowledge for firms in a model of growth of innovative firms and industries see Klette and Kortum (2004).

${ }^{10}$ Since citations are distinguished by citing and cited field, university and year they are six dimensional. In our notation subscripts stand for the three citing dimensions, while superscripts stand for cited dimensions. The order of sub- (super-) scripts is always: field, university, and year.
} 
This is the sum of R\&D expenditures $r_{k F \tau-z}$ in a university-field over the previous eight years, in millions of '92 dollars, and assuming a depreciation rate $d=0.15$. R\&D flows are drawn from NSF’s CASPAR database (NSF, 2009a). To reduce simultaneity bias we lag (5) in production function (3). We enter (5) as a separate variable to account for past resources of a universityfield not captured by knowledge-flows, so that we use R\&D stock of a university-field in two distinct ways: first as an indicator of tangible resources in (5), and second as a stock of knowledge produced by those resources in (4). This double-duty reflects the dual nature of past research activity in a university-field.

The flow of outside knowledge from other universities is

$$
S_{i j t}^{\text {OtherUniversities }}=\sum_{F=1}^{M} \sum_{k \neq j}^{N} \sum_{\tau=1}^{t-1}\left(c_{i j t}^{F k \tau} / n_{F k \tau}\right) \mathrm{R}_{F k \tau}
$$

It is the sum over all fields, other universities, and previous years.

The same field knowledge-flow is

$$
S_{i j t}^{\text {Same Field }}=\sum_{k=1}^{N} \sum_{\tau=1}^{t-1}\left(c_{i j t}^{i k \tau} / n_{i k \tau}\right) \mathrm{R}_{i k \tau}
$$

In (7) the sum is taken over the same field, all universities, and previous years.

The knowledge-flow from other fields, or the interdisciplinary flow, is

$$
S_{i j t}^{\text {Other Fields }}=\sum_{F \neq 1}^{M} \sum_{k=1}^{N} \sum_{\tau=1}^{t-1}\left(\mathrm{c}_{i j t}^{F k \tau} / n_{F k \tau}\right) \mathrm{R}_{F k \tau}
$$

It is the sum over other fields, all universities, and previous years. Besides (4), (6)-(8) we consider mixtures: $S_{i j t}^{\text {Same Field, Same University }}, S_{i j t}^{\text {Other Fields, Same University }}, S_{i j t}^{\text {Same Field, Other Universities }}$, and $S_{i j t}^{\text {Other Fields, Other Universities }}$. All these variables are citation-weighted R\&D stocks but let us call them knowledge-flows. Sometimes the flows equal zero, so to take logarithms we add 0.001 to each of the flows. 
For descriptive purposes we consider a scale-free measure of interdisciplinary research.

From (7) and (8) this is the interdisciplinary share in knowledge flows in field $i$ at timet:

$$
\text { Share }_{\text {it }}^{\text {Other Fields }}=\frac{S_{\text {it }}^{\text {Other Fields }}}{S_{\text {it }}^{\text {Same Field }}+S_{\text {it }}^{\text {Other Fields }}}
$$

Likewise, using (4) and (6), we consider the share of outside knowledge-flows:

$$
\text { Share }_{i t}^{\text {Other Univs }}=\frac{S_{i t}^{\text {Other Universities }}}{S_{i t}^{\text {SameUniversity }}+S_{\text {it }}^{\text {Other Universities }}}
$$

With all of our preparations complete, we are ready for the empirical work.

\section{Description of the Knowledge-Flows}

\section{A. Field Size Distribution}

Figure 1 and 2 display average knowledge-flows to each of the citing fields. Figure 1 covers "large” R\&D fields: engineering, chemistry, agriculture, physics, earth science, medicine, and biology. Figure 2 covers "small" fields: mathematics and statistics, economics and business, computer science, astronomy, and psychology. The smallest "large" field, engineering, has a knowledge flow more than twice that of the largest "small” field, psychology. Flows to biology and medicine exceed all the others. These differences follow the distribution of academic R\&D by field, since most citations occur within a field, and since, according to (7) and (8), the flows are sums of cited R\&D stocks weighted by citation rates ${ }^{11}$.

\section{B. Sources of Interdisciplinary Knowledge-Flows}

Table 1 examines sources of interdisciplinary knowledge-flows by citing field. The table lists the three most cited fields for years 1983, 1991, and 1999. Biology and medicine become

\footnotetext{
${ }^{11}$ National Science Board (2008), Appendix Table 5-4 contains the following data from 1999 on the percentage distribution of R\&D expenditures by field: agriculture, 7.4\%; astronomy, $1.4 \%$; biology, $18.3 \%$; chemistry, 3.3\%; computer science, $3.1 \%$; earth and environmental sciences, $6.1 \%$; economics and business, $1.0 \%$; engineering, 15.6\%; mathematics and statistics, $1.1 \%$; medicine, $29.1 \%$; physics, $4.2 \%$, psychology, $1.7 \%$, and all other, $7.7 \%$.
} 
more important over time while engineering and physics become less important. This pattern corresponds to the growing share of the life sciences in university R\&D.

\section{Changes in Interdisciplinary Shares over Time}

Figures 3a to 31 depict time series of the interdisciplinary share by field. The share rises in agriculture, biology, chemistry, earth sciences, engineering, mathematics, and psychology. It increases most in engineering, where it rises by 77 percent of its 1983 value; and in mathematics and statistics, where it rises by 70 percent. As Section II.B has shown, these fields are the primary objectives of policies that seek to increase interdisciplinary research. But the share declines in astronomy, computer science, and physics. Over the entire period there is no change in economics and business or in medicine.

Figure 4 depicts time series of the average interdisciplinary share. It increases by 10 percent, from 0.22 to 0.24 . In Figure 5 the outside share increases by 32 percent, from 0.62 to 0.82. The interdisciplinary share increases slightly, but the rise in the outside share is large.

\section{The Engineering Subfields}

The interdisciplinary share grows fastest in engineering (Figure 3h). To identify the sources of this change we study the relationship between the engineering subfields and the rest of engineering and science outside engineering — the remaining 11 fields in Figure 3. At this level we cannot construct citation-weighted $\mathrm{R} \& \mathrm{D}$, but we can construct citations. We use citation shares for the same subfield, other engineering, and science to show relative importance. The share is: CiteShare ${ }_{t}^{j}=$ Citations ${ }_{t}^{j} / \sum_{i}$ Citations ${ }_{t}^{i}$ where $i, j$ stand for same subfield, other engineering, and science, and $t$ stands for year. Table 2 shows long differences in citation shares over the period 1983 to 1999 . In 11 of 13 cases the citation share of the same subfield decreases and in eight the decrease exceeds 0.1 . In nine cases the share of science increases and in six it 
increases by more than 0.1 . Changes in other engineering are positive but small. Clearly citations move towards science and away from engineering.

Science citation shares rise sharply in Artificial Intelligence, Robotics, and Automation; Civil Engineering; Chemical Engineering; Environmental Engineering \& Energy; Biomedical Engineering; and Materials Science. Accordingly, Figure 6 examines knowledge-flows from science outside engineering for these subfields ${ }^{12}$. The figures are area graphs that break out the top five sciences and treat all others as a residual. Citations to computer science and biology rise noticeably in Artificial Intelligence, Robotics, and Automation. In Civil Engineering flows from biology and the earth sciences increase most. In Chemical Engineering biology, physics and chemistry are the source of the increased role for science. The share of biology increases in Environmental Engineering \& Energy, while the share of medicine increases in Biomedical Engineering. Citations to physics and biology increase markedly in Materials Science.

\section{E. Mathematics and Statistics}

Figure 3i shows that the interdisciplinary share rises sharply in mathematics. For this reason Figures 7a and 7b take a closer look at the interdisciplinary share of citations for pure and applied mathematics and statistics. Figure 7 is comparable to Figure 6.

The increase in the interdisciplinary share is slight in these fields compared with engineering. In pure and applied mathematics (Figure 7a) most of this comes from physics, and other fields stay the same. In statistics most of the increase derives from biology and medicine (Figure 7b). The growing life science link is with statistics and not pure and applied mathematics.

We have seen that the interdisciplinary share increases in engineering, mathematics and a few other fields. But idea-flows may increase because of policy push rather than demand pull. It

\footnotetext{
${ }^{12}$ Figure 6 excludes citations to engineering since its purpose is to examine citations to science.
} 
is critical to distinguish the productive importance of a field from its share in knowledge-flows, as the following regression analysis points out.

\section{Regression Analysis of Universities}

We turn now to estimates of knowledge production function (3) using the evidence on U.S. universities described in Sections IV and V. Table 3 contains descriptive statistics. Arithmetic means and standard deviations appear above, while values in logarithms appear in parentheses below. About 200 papers are written per year. During their first five years, the papers earn 440 citations from other U.S. universities.

Following (4)-(8), the mean knowledge-flow (of citation-weighted R\&D) is 677 million dollars. Three-fourths of this (519 million) occurs within a field, while one-fifth (144 million) occurs within a university. As one might expect, same field and other universities dominate the knowledge-flows. The average R\&D stock of a university-field is 82 million dollars.

Table 4 reports regressions that divide knowledge-flows into flows from the same and other universities. Equations 4.1-4.3 use the logarithm of papers as the dependent variable while 4.4-4.6 use the logarithm of citations received. All equations include fixed effects for field, university, and year that absorb persistent errors that are correlated with the knowledge- flows and the R\&D stock. Knowledge inputs are lagged to avoid correlation with the transitory error $e_{i j t}$. Standard errors are robust and adjusted for clustering by university. Equations 4.1 (4.4) include logarithms of the R\&D stock of a university-field and the total knowledge-flow. The output elasticity of R\&D stock is $0.17(0.17)$, while the output elasticity of the total knowledge flow is 0.40 (0.48), so that knowledge-flows are more important. Equations 4.2 and 4.5 break up the knowledge-flows into inside flows from the same university and outside flows from other 
universities $^{13}$. The inside elasticities in $4.2(4.5)$ are $0.07(0.08)$, while the outside elasticities are 0.29 (0.35): outside flows are more important. Equations 4.3 and 4.6 explore whether inside or outside knowledge-flows have become more or less important over time. To address this we construct an indicator variable $I($ year in the $1990 \mathrm{~s})$. I(•) equals one if a year is in the 1990s and zero otherwise. We interact $I(\bullet)$ with the inside and outside knowledge-flows to see whether the importance of a knowledge-flow changes in the 1990s, a period of rapid change in information technology and in science policy. The specification is

$$
\begin{aligned}
\ln \left(n_{i j t}\right)= & \beta+Z_{D}^{\prime} \delta+\eta_{R} \ln \left(R_{j, t-1}\right)+\sum_{w=1}^{W} \eta_{w} \ln \left(S_{(i j) t-1}^{w}\right)+ \\
& \sum_{w=1}^{W} \phi_{w} I(\text { year in the } 1990 s) \bullet \ln \left(S_{(i j) t-1}^{w}\right)+e_{i j t}
\end{aligned}
$$

Coefficients of the interactions $\phi_{w}$ will be positive (negative) if a given knowledge-flow has a rising (falling) effect ${ }^{14}$. Notice that the interactions are in addition to time effects in $Z_{D}^{\prime}$ : they represent the changing importance of knowledge-flows associated with technology and policy in the 1990s, while time effects capture trends in papers that are not caught by the other variables.

The results appear in equation 4.3 (4.6). The main elasticity $\eta_{w}$ of knowledge-flows from the same university equals $0.08(0.09)$. The interaction elasticity for the 1990 s is $-0.05(-0.08)$. All effects differ significantly from zero. Note that inside knowledge-flows become less important over time. The main elasticity of knowledge-flows from other universities in 4.3(4.6) is $0.26(0.32)$ and the interaction elasticity for the 1990 s is $0.13(0.21)$. Thus outside knowledgeflows become more important. Also, growth in the outside elasticity exceeds decline in the inside elasticity so the importance of knowledge-flows increases. Another way to put this is that

\footnotetext{
${ }^{13}$ Separation of the variables introduces additional errors in the variables, indicated by the decline in the sum of the separate elasticities in 4.3 and 4.6 below the combined elasticities in 4.2 and 4.5, by a slight drop in R-squared, and by a slight increase in the root mean squared error. A useful reference on this point is Hausman (2001).

14 Since the Cobb-Douglas does not capture factor-biased technological change, we have augmented the function by including interactions of the elasticities with time.
} 
knowledge-flows make a larger contribution to research output during the $1990 \mathrm{~s}^{15}$. This growing contribution is significant at the one percent level in 4.3 and $4.6^{16}$. It almost surely reflects advances in information technology and infrastructure (Adams et al., 2005).

Table 5 divides knowledge-flows into flows from the same field and other fields. 5.1-5.3 report findings for papers while 5.4-5.6 report findings for citations received. As before the logarithm of R\&D stock of the university-field is included to control for tangible resources. 5.1 and 5.4 include two knowledge-flows, from the same and other fields. 5.2 and 5.5 include four flows: from the same and other fields and universities. Following equation (11), 5.3 and 5.6 add interactions of logarithms of knowledge-flows from the same and other fields with a dummy for the 1990s.

In equation 5.1 (5.3), the elasticity of same field knowledge-flows is $0.30(0.37)$ while the elasticity of flows from other fields is $0.08(0.07)$. The same field elasticity is four times larger than the elasticity of other fields, though both are significant.

In equation 5.2 (5.5) we see that the same field/same university elasticity is $0.04(0.04)$ while the same field/other university elasticity is $0.21(0.27)$. Most of the productive impact of knowledge from the same field comes from outside a university.

This is not true of interdisciplinary knowledge-flows. In 5.2 (5.5) the other field/same university elasticity is 0.04 (0.03), while the other field/other university elasticity is $0.04(0.04)$. Importance of interdisciplinary flows is distributed equally across same and other universities. This suggests that scientists from different fields must spend substantial time together and this would explain the comparative localization of interdisciplinary flows.

\footnotetext{
15 The statement that knowledge-flows make an increasing contribution to scientific discoveries is not the same as saying that productivity increases. In fact growth of university output slows down in the 1990s, despite the growing contribution of knowledge-flows (Adams, forthcoming 2010).

${ }^{16}$ Using (11), the F-statistic for the null hypothesis of the restriction $\phi_{\text {Inside }}+\phi_{\text {Outside }}=0$ is $\mathrm{F}(1,109)=96.4$ in 4.3 . For 4.6 the F-statistic is $\mathrm{F}(1,109)=159.5$. In both cases the test decisively rejects the null.
} 
Following (11) equations 5.3 and 5.6 examine changes over time. In 5.3 (5.6) we see that the main elasticity of knowledge-flows in the same field is $0.28(0.35)$, while the elasticity of the interaction of this elasticity with the 1990s is 0.07 (0.11). All estimates differ significantly from zero and the same field elasticity increases with time. In 5.3 (5.6), the main elasticity of knowledge-flows from other fields is $0.09(0.08)$. But the interaction elasticity is $0.01(0.01)$ and insignificant. While positive and significant, the interdisciplinary elasticity stays the same over time. Therefore, the importance of same field knowledge-flows increases relative to that of interdisciplinary flows.

Growth in the same field elasticity combined with an insignificant increase in the interdisciplinary elasticity implies, just as in Table 4, that knowledge-flows are more important in the 1990s. The sum of the interaction elasticities differs significantly from zero in 5.3 and $5.6^{17}$

Since engineering and mathematics are a focal point of policies favoring interdisciplinary research, we analyze research output of the two fields using an equation like 5.3. The logarithm of papers is the dependent variable:

$$
\begin{aligned}
\log (\text { Papers })= & 0.098^{* *} \bullet \log (\text { Knowledge }- \text { Flow, Same Field }) \\
& (0.032) \\
+ & 0.103 * * \bullet I(\text { Year in the } 90 \mathrm{~s}) \bullet \log (\text { Knowledge }- \text { Flow, Same Field }) \\
& (0.032) \\
+ & 0.017 * \bullet \log (\text { Knowledge }- \text { Flow, Other Fields }) \\
& (0.008) \\
- & 0.034 * \bullet I(\text { Year in the } 90 s) \bullet \log (\text { Knowledge }- \text { Flow, Other Fields }) \\
& (0.015) \\
+ & \text { other terms } \quad R^{2}=0.92, N=1,955
\end{aligned}
$$

${ }^{17}$ Using (11) the F-statistic for the null hypothesis of the restriction $\phi_{\text {SameField }}+\phi_{\text {Other Field }}=0$ is F $(1,109)=98.5$ in 5.3. For 5.6 the F-statistic is F $(1,109)=129.7$. Again the tests decisively reject the null. 
The elasticity of knowledge-flows in the same field doubles over time. In contrast, the interdisciplinary elasticity declines. The productive importance of knowledge-flows in the same field increases by a larger proportion in the very disciplines where interdisciplinary research is a policy goal. This suggests that policies promoting interdisciplinary research, described in Section II.B and reflected in growth of interdisciplinarity in Section V, Figure 3-h and 3-i, are being overridden, perhaps by changes in information technology (see Section VIII below).

Returning to the broader sample, we explore the changing importance of outside fields using an alternative specification. We are interested in whether growth in the share of knowledge-flows from other fields individually indicates growing importance in the production of scientific papers. Put differently, are "hot" fields more productive in fields that cite them and does this advantage grow over time? The answer turns out to be, not consistently.

To identify "hot” fields, recall from Table 1 that shares of some outside fields increase in knowledge-flows to particular sciences. A case in point is the rising share of biology in knowledge-flows to agriculture ${ }^{18}$. Other examples include the rising importance of medicine in biology, and of computer science, engineering, and medicine in mathematics. To define "hot" fields we count all external fields, relative to each citing field, whose shares in knowledge-flows increase by at least one percent from 1983 to 1999. All other fields are designated "cold” fields. But if no outside field increases its share then there are no "hot" fields and knowledge flows from "hot" fields equal zero.

Table 6 shows "hot" fields for each citing field. Biology, medicine, computer science and engineering dominate among "hot" fields. Also notice that astronomy, computer science, earth sciences, medicine, and physics have no "hot" fields assigned to them. The reason is that

\footnotetext{
${ }^{18}$ This probably reflects the growing usefulness of genetic engineering in plant breeding (Ruttan 2001, Chapter 10).
} 
the share of external fields in knowledge-flows declines over time for these disciplines. Using the information in Table 6, consider the following specification:

$$
\begin{gathered}
\ln \left(n_{i j t}\right)=\beta+Z_{D}^{\prime} \delta+\eta_{R} \ln \left(R_{j, t-1}\right)+\eta_{\text {Same }} \ln \left(S_{(i j) t-1}^{\text {Same Field }}\right)+ \\
\eta_{\text {"Hot" }} \ln \left(S_{(i j) t-1}^{\text {"Hot"Other Fields }}\right)+\eta_{\text {"Cold" }} \ln \left(S_{(i j) t-1}^{\text {"Cold"Other Fields }}\right)+e_{i j t}
\end{gathered}
$$

A crucial test is whether the hypothesis $\eta_{\text {"Hot" }}=\eta_{\text {"Cold" }}$ is accepted. If it is then "hot" fields are not more productive than "cold” fields. This would cast doubt on the idea that "hot" fields underpin growth in interdisciplinary research.

For some citing disciplines there are no "hot" fields and the logarithm is that of zero (augmented by 0.001). We therefore modify (13) by adding an interaction of the logarithm of knowledge-flows from "hot" fields with an indicator I ("Hot" Fields $=0$ ). This equals one if true and zero otherwise. Although less common, we introduce a similar indicator for the absence of knowledge flows from “cold” fields: I("Cold " Fields $=0$ ). The revised specification is,

$$
\begin{gathered}
\ln \left(n_{i j t}\right)=\beta+Z_{D}^{\prime} \delta+\eta_{R} \ln \left(R_{j, t-1}\right)+\eta_{\text {Same }} \ln \left(S_{(i j) t-1}^{\text {Same Field }}\right)+\eta_{" H o t "} \ln \left(S_{(i j) t-1}^{\text {"Hot"Other Fields }}\right)+ \\
\theta_{\text {"Hot" }} I\left(" H o{ }^{\prime \prime} \text { Fields }=0\right) \bullet \ln \left(S_{(i j) t-1}^{\text {"Hot Other Fields }}\right)+\eta_{\text {"Cold" }} \ln \left(S_{(i j) t-1}^{\text {"Cold"Other Fields }}\right)+ \\
\theta_{\text {"Cold" }} I(" \text { Cold" Fields }=0) \bullet \ln \left(S_{(i j) t-1}^{\text {"Cold"Other Fields }}\right)+e_{i j t}
\end{gathered}
$$

The “zero interaction” terms $\theta_{i}$ absorb the effect of the absence of knowledge-flows from other fields, which biases the main elasticities $\eta_{i}$ towards zero.

Finally, it is useful to test for changes over time in the comparative importance of same field as well as "hot” and "cold” other fields, by interacting logarithms of the knowledge-flows with an indicator variable for the 1990s. This specification extends that of (14):

$$
\begin{gathered}
\ln \left(n_{i j t}\right)=\beta+Z_{D}^{\prime} \delta+\eta_{R} \ln \left(R_{j, t-1}\right)+\eta_{\text {Same }} \ln \left(S_{(i j) t-1}^{\text {Same Field }}\right)+\eta_{" H o t "} \ln \left(S_{(i j) t-1}^{" H o t " \text { Other Fields }}\right)+ \\
\theta_{\text {"Hot" }} I(" H o t " \text { Fields }=0) \times \ln \left(S_{(i j) t-1}^{\text {"Hot"Other Fields }}\right)+\eta_{" C o l d "} \ln \left(S_{(i j) t-1}^{\text {"Cold"Other Fields }}\right)+ \\
\theta_{\text {"Cold" }} I(" \text { Cold" Fields }=0) \times \ln \left(S_{(i j) t-1}^{\text {"Cold"Other Fields }}\right)+ \\
\sum_{w \in " \text { Same","Hot","Cold" }} \phi_{w} I(\text { year in the } 1990 s) \bullet \ln \left(S_{(i j) t-1}^{w}\right)+e_{i j t}
\end{gathered}
$$


The summation in the last line consists of interactions of knowledge-flows with the 1990s indicator. We shall use (13)-(15) together to study same, "hot”, and “cold” fields.

Table 7 shows the results. As in previous tables the dependent variable in 7.1-7.3 is the logarithm of papers while in 7.4-7.6 it is the logarithm of citations received. All equations include R\&D stock and same field flows, but since results for these variables are the same, we concentrate on "hot" and "cold" field elasticities. For papers the elasticity of "hot" fields is less than that for "cold" fields, and this difference is sometimes significant. But for citations the elasticity of "hot" fields exceeds that of "cold". And yet the "hot" field elasticity is not consistently greater than that for "cold” fields.

Following (13), 7.1 (7.4) introduce logarithms of these variables without interactions. Following (14), 7.2 (7.5) introduce zero interactions. As expected the sign of the zero interaction terms is negative and significant. Accounting for zero knowledge flows increases the main elasticities of "hot" fields and "cold" fields in 7.2 but it does not change their relative size. In 7.3 (7.6) we use specification (15), which allows for a full set of interactions between the knowledge-flows and the indicators for zero knowledge-flows and the 1990s. The elasticities of "hot" and "cold" increase or decrease slightly but at the same rate. "Hot" fields are not becoming more important over time relative to "cold" fields. Moreover, knowledge-flows from the same field are becoming more important than either one. The hypothesis of an increasing role for interdisciplinary research in the production of scientific research is rejected.

\section{Regression Analysis of Firms}

So far we have considered the top 110 U.S. universities, emphasizing inside, outside, and interdisciplinary knowledge-flows, and their role in the production of scientific papers. While our main interest is in academic science, a comparison with firms is nevertheless useful. Table 8 
repeats the analysis using a panel of firms, fields, and years ${ }^{19}$. The firms are the 200 largest U.S.based performers of $R \& D$ and citations take place among these firms. The dependent variable is the logarithm of the firm's fractional papers ${ }^{20}$. Table 8 for firms combines the main features of Tables 5 and 7, which deal with interdisciplinary research in universities.

Equations 8.1 and 8.2 are counterparts to 5.1 and 5.3. In 8.1 the output elasticity of same field knowledge-flows is 0.24 , while the elasticity for other fields is 0.09 . These estimates are similar to the elasticities that equation 5.1 reported for universities, which are 0.30 and 0.08 . As with 5.3 for universities, in 8.2 for firms we add interactions of the knowledge-flows with an indicator for the 1990s. The elasticity of knowledge-flows from the same field increases significantly over time, from 0.21 in the 1980 s to 0.26 in the 1990 s. This is similar to the increase from 0.28 to 0.34 observed in 5.3 for universities.

The rest of Table 8 concerns knowledge-flows from "hot” and “cold” external fields. Equations 8.3-8.5 are analogous to the university equations 7.1-7.3. All equations include logarithms of the firm's basic research stock and of same field knowledge-flows, with similar results to 8.1 and $8.2^{21}$. Equation 8.3 includes logarithms of "hot” and “cold” fields, whose elasticities are 0.04 and 0.09 . The estimates are significant at the one percent level, but the elasticity for "hot" fields is significantly less than that for "cold” fields. It is useful to include a zero interaction between the logarithm of knowledge-flows from other fields and an indicator for zero knowledge-flows. When this is done, in 8.4, the zero interactions are again negative and significant, and main elasticities increase. The elasticity for "hot” fields (0.136) remains less than

\footnotetext{
${ }^{19}$ See Adams and Clemmons (2008) for a detailed description of the firm panel.

${ }^{20}$ Since citations received by firm papers exhibit a substantial number of zeroes, they require the use of Tobit analysis. While there is nothing difficult about undertaking such an analysis or in comparing expected marginal effects in Tobit analysis to regression coefficients, such an analysis lies outside the scope of the present paper. ${ }^{21}$ As Adams and Clemmons (2008) show, total R\&D stocks of firms are weighted by the share of basic research in their primary industry to arrive at an estimate of the basic research stock for the firms.
} 
that for "cold" fields (0.190) but the difference is not significant. Equation 8.5 adds interactions between logarithms of knowledge-flows for the same, "hot", and "cold" fields with the 1990s dummy. The same field elasticity increases significantly, from 0.19 in the 1980 s to 0.24 in the 1990s. The "hot" and "cold" field elasticities decline but the decline is not statistically significant. The university and firm estimates agree in that elasticities of "hot" and "cold" fields change rather little whereas the same field elasticity increases. The results for firms are similar to those for universities, perhaps because underlying incentives are similar across sectors.

\section{Summary, Discussion, and Conclusion}

This paper finds that outside knowledge-flows from other institutions, and the importance of outside knowledge for research output measured by scientific papers and citations received, have risen relative to inside knowledge-flows from the same university (Table 4). Results on knowledge-flows from the same field and other fields are more complex than this and more tentative. Same field and interdisciplinary flows contribute positively and significantly to scientific papers. The main facts to be reconciled are that interdisciplinary knowledge-flows in universities increase slightly as a share of all knowledge-flows (Figure 4), but the importance of interdisciplinary knowledge in the production of new ideas does not increase, even as the same field elasticity increases (Table 5). ${ }^{22}$

When we break up knowledge-flows from other fields into "hot" (shares in knowledge-flows rising) and "cold" (shares flat or declining) in Table 7 the importance of "hot" fields in production also does not increase relative to "cold” fields. Besides this, "hot” fields are not

\footnotetext{
${ }^{22}$ Importance in production is again measured by the elasticity of research output with respect to knowledge-flows.
} 
consistently more important than "cold" fields ${ }^{23}$. These results hold for firms as well as universities (Table 8).

The most important changes in the structure of production of scientific discoveries are as follows. During the 1990s the structure of production shifts towards outside knowledge-flows from other universities (Table 4) while at the same time it begins to favor same field knowledgeflows (Table 5). In both cases knowledge-flows make a larger contribution in the 1990s. At this point we offer a few observations.

Adams et al. (2005) find that outside collaboration increases because of construction of the Internet and its connection to networks in Europe and Asia in the late 1980s (Mowery and Simcoe, 2002). In the 1980s the Internet became a policy initiative of the NSF and the same is true of cyber infrastructure today (National Science Foundation, 2009b). Not merely collaboration but also citation would shift outside a university as a result of this infrastructure. More subtly, distant researchers in the same discipline become collaborators. They can replace researchers in the same university but other disciplines (Rosenblat and Mobius, 2004).

It follows that growth of information technology could have brought about a decrease in the importance of interdisciplinary research. To produce the increase in Figure 4, however slight, would require at least one countervailing factor. From Section II.B, one candidate for such a factor is the founding of university research centers starting in the 1980s, whose purpose is to encourage interdisciplinary research (Adams, Chiang and Starkey, 2001). Since the 1980s many other centers have been founded, including in nanotechnology. Many encourage industry involvement and because industrial research tends to cut across fields, this too would encourage interdisciplinary research (Boardman and Corley, 2008). Important as well are large government

\footnotetext{
${ }^{23}$ Thirdly, the correlation by field between growth in the share of outside fields in knowledge-flows and the importance of other fields in production of new ideas is probably low based on Figures 3a-3l and Table 6.
} 
programs, such as the Human Genome Project, which marshal vast resources with one purpose being that of encouraging scientists in different fields to combine their talents.

All of this tells a story of simultaneous pursuit of different goals with sometimes unforeseen consequences. By supporting information technology NSF intended to connect, and did connect, more researchers in joint research. By establishing university centers NSF meant to engage more researchers in interdisciplinary research. This is because, given the growing complexity of scientific questions, NSF strongly holds the view that interdisciplinary research leads to more breakthroughs (National Science Foundation, 2009b). The unforeseen consequence was that cyber infrastructure would promote research within the same field rather than interdisciplinary research even though the goal of the centers was to promote interdisciplinary research (Rosenblat and Mobius, 2004).

None of the findings in this paper should be seen as "closing the book" on interdisciplinary research—far from it. We must not rush to judgment and argue that deliberate subsidization of interdisciplinary research is mistaken but instead wait and maintain a patient agnosticism until the results of the policy can be observed. While a final verdict is yet to be rendered, one interpretation of the findings is that interdisciplinary research is still in its early stages. Although interdisciplinary knowledge-flows have increased a little, this is partly because of recent policies designed to support them. What we may not be seeing so far are the effects of discoveries from this research that would increase the importance of interdisciplinary research in the next generation of discoveries. Those events could still lie in the future. This would be true if gestation lags on interdisciplinary work are long and variable, precisely because the work is path-breaking. One must learn to live with ambiguities relating to new policies like those that we study in this paper, just as with the study of new phenomena in general. 


\section{References}

Adams, James D., “Is the U.S. Losing Its Preeminence in Higher Education?”, Cambridge, MA, NBER Working Paper \#15233, August 2009, forthcoming in Charles T. Clotfelter, editor, American Universities in a Global Market, Chicago: University of Chicago Press for the National Bureau of Economic Research, 2010 , Eric P. Chiang, and Katara Starkey, “Industry-University Cooperative

Research Centers,” Journal of Technology Transfer 26 (January 2001): 73-86 , “Comparative Localization of Academic and Industrial Spillovers,” Journal

of Economic Geography 2 (July 2002): 253-278 , and Zvi Griliches, "Research Productivity in a System of Universities,"

Annales D’Economie et de Statistique 49/50 (1998): 127-162

, Grant Black, J. Roger Clemmons, and Paula E. Stephan, “Scientific Teams

and Institutional Collaborations: Evidence from U.S. Universities, 1981-1999,” Research

Policy 34 (2005): 259-285

, J. Roger Clemmons, and Paula E. Stephan, "Standing on Academic

Shoulders: Measuring Scientific Influence in Universities," forthcoming, Annales

D’Economie et de Statistique, 2006 , and J. Roger Clemmons, “The NBER-Rensselaer

Scientific Papers Database: Form, Nature, and Function,” Cambridge, Mass., NBER

Working Paper 14575, December 2008

Becker, Gary S., and Kevin M. Murphy, “The Division of Labor, Coordination Costs, and

Knowledge,” Quarterly Journal of Economics CVII (November 1992): 1137-1160

Boardman, P. Craig, and Elizabeth Corley, "University Research Centers and the Composition of 
Research Collaborations,” Research Policy 37 (2008): 900-913

Corley, Elizabeth, P. Craig Boardman, and Barry Bozeman, "Design and the Management of Multi-Institutional Research Collaborations: Theoretical Implications from Two Case Studies,” Research Policy 35 (2006): 975-993

Committee on Science, Engineering, and Public Policy: National Academy of Sciences, National Academy of Engineering, and Institute of Medicine, Facilitating Interdisciplinary Research, Washington, DC: National Academies Press, 2004

Hausman, Jerry, "Mismeasured Variables in Econometric Analysis: Problems from the Right and Problems from the Left,” Journal of Economic Perspectives 15 (Fall 2001): 57-68 Hicks, Diana, and J. Sylvan Katz, "Science Policy for a Highly Collaborative Science System,” Science and Public Policy 23: 39-44

Hirshleifer, Jack, and John G. Riley, The Analytics of Uncertainty and Information, New York, Cambridge University Press, 1992

Holton, Gerald, Hasok Chang, and Edward Jurkowitz, "How a Scientific Discovery is made: A Case History,” American Scientist 84 (July/August 1996): 364-375

Hounshell, David, and John Kenley Smith, Science and Corporate Strategy: DuPont R\&D, 1902-1980, New York: Cambridge University Press, 1988

Hsiao, Cheng, Analysis of Panel Data, $2^{\text {nd }}$ Edition, Cambridge, UK and New York: Cambridge University Press, 2003

Jeffrey, Paul, "Smoothing the Waters: Observations on the Process of Cross-Disciplinary Research,” Social Studies of Science 33 (August 2003): 539-562

Katz, J. Sylvan, and Ben R. Martin, “What is Research Collaboration” Research Policy 26 (1997): $1-18$ 
Klette, Tor Jakob, and Samuel Kortum, “Innovating Firms and Aggregate Innovation,” Journal Of Political Economy 112 (October 2004): 986-1018

Kortum, Samuel, “Research, Patenting, and Technological Change,” Econometrica 65 (November 1997): 1389-1419

Mowery, David C., and Timothy Simcoe, "Is the Internet a U.S. Invention?-an Economic and Technological History of Computer Networking” Research Policy 31 (2002): 1369-1387

National Institutes of Health, National Institute of Allergy and Infectious Diseases, Bioinformatics Resource Centers, www.miaid.nih.gov/LabsandResources/brc

National Research Council, Research-Doctorate Programs in the United States: Continuity And Change, Washington, DC: National Academy Press, 1995

National Science Board, Science and Engineering Indicators 2002 (in two volumes), Arlington, VA, National Science Foundation, 2002 , Science and Engineering Indicators 2008 (in two volumes),

Arlington, VA, National Science Foundation, 2008

National Science Foundation, CASPAR (Computer-Aided Science Policy Analysis and Research) Database, www.nsf.gov/statistics, Arlington, VA, 2009a , “NSF-Wide Investments,” www.nsf.gov/news/priority_areas, $2009 b$

Nelson, Richard R., "The Link between Science and Invention: The Case of the Transistor," in Richard R. Nelson, editor, The Rate and Direction of Inventive Activity: Economic and Social Factors, Princeton, NJ: Princeton University Press for NBER, 1962 , “The Role of Knowledge in R\&D Efficiency,” Quarterly Journal of Economics 97 (August 1982): 453-470 
Price, Derek J. de Solla, Big Science, Little Science, and Beyond, Revised edition, New York: Columbia University Press, 1986

Rosenblat, Tanya S., and Markus M. Mobius, “Getting Closer or Drifting Apart” Quarterly Journal of Economics CXIX (August 2004): 971-1010

Ruttan, Vernon W., Technology, Growth, and Development, Oxford: Oxford University Press, 2001

Zuckerman, Harriet, and Robert K. Merton, “Age, Aging, and Age Structure in Science,” in Robert K. Merton, and Norman W. Storer, editors, The Sociology of Science: Theoretical and Empirical Investigations, Chicago: University of Chicago Press, 1973 
Figure 1--Mean Annual Knowledge-Flows (in mill. of ' $92 \$$ ), Seven Large Academic Fields, 1983-1999

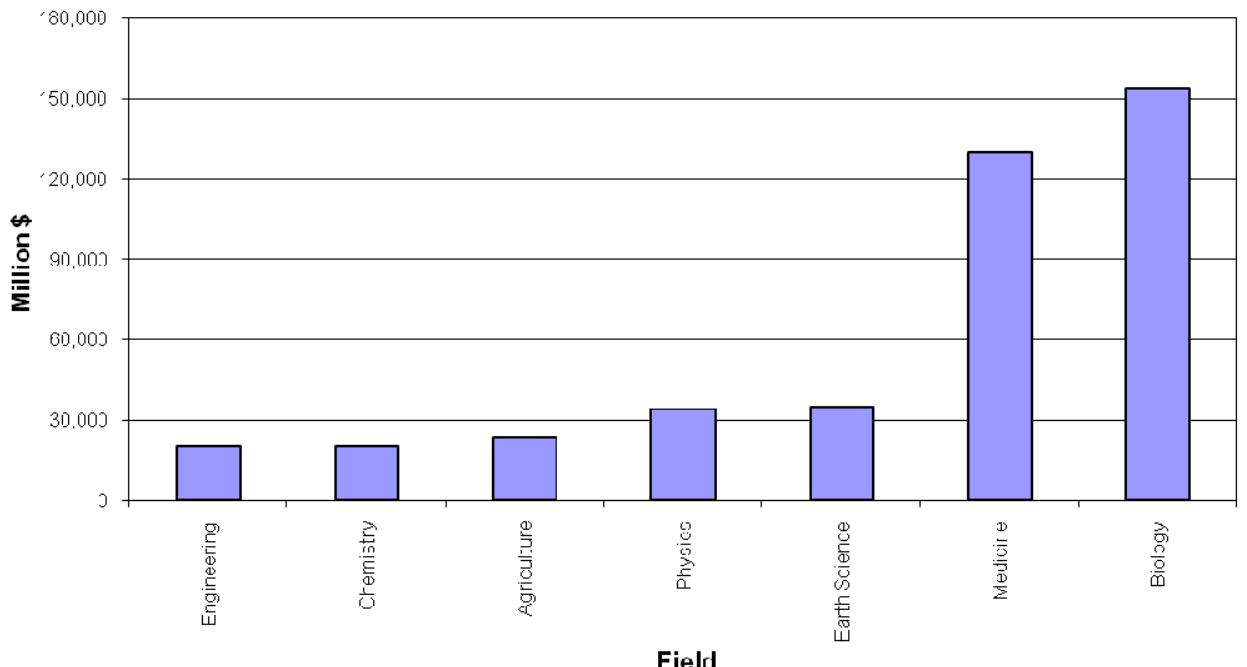

Figure 2--Mean Annual Knowledge-Flows (in mill. of '92 \$), Five Small Academic Fields, 1983-1999

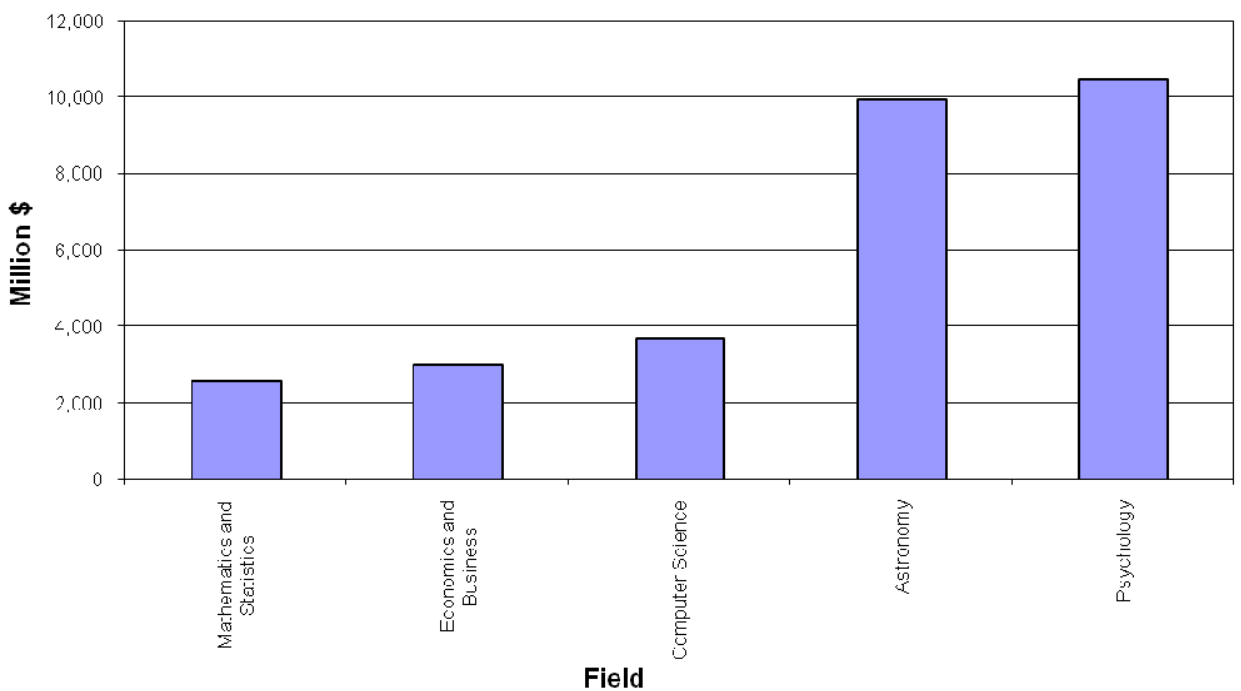


Figure 3a-Share of Other Fields,

Knowledge-Flows to Agriculture

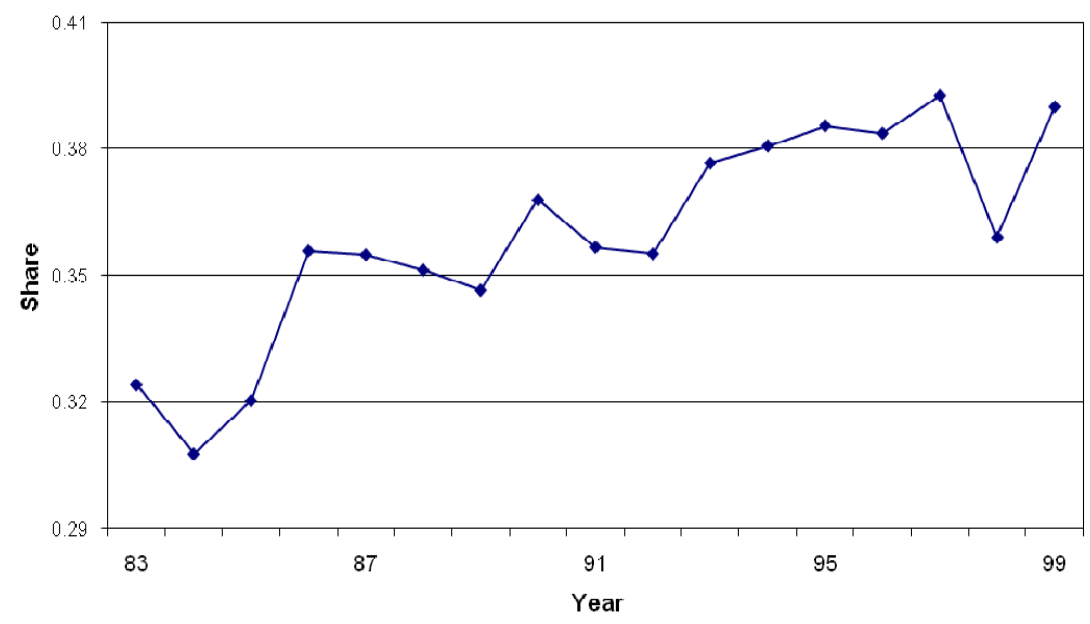

Figure 3b--Share of Other Fields,

Knowledge Flows to Astronomy

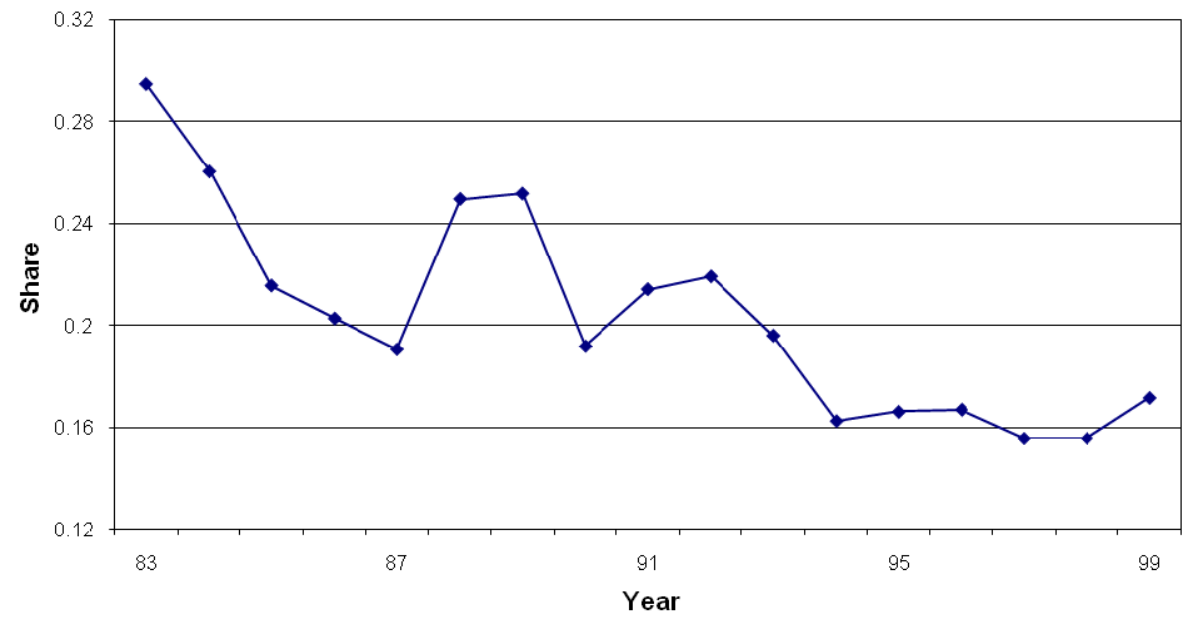

Figure 3c--Share of Other Fields,

Knowlege-Flows to Biology

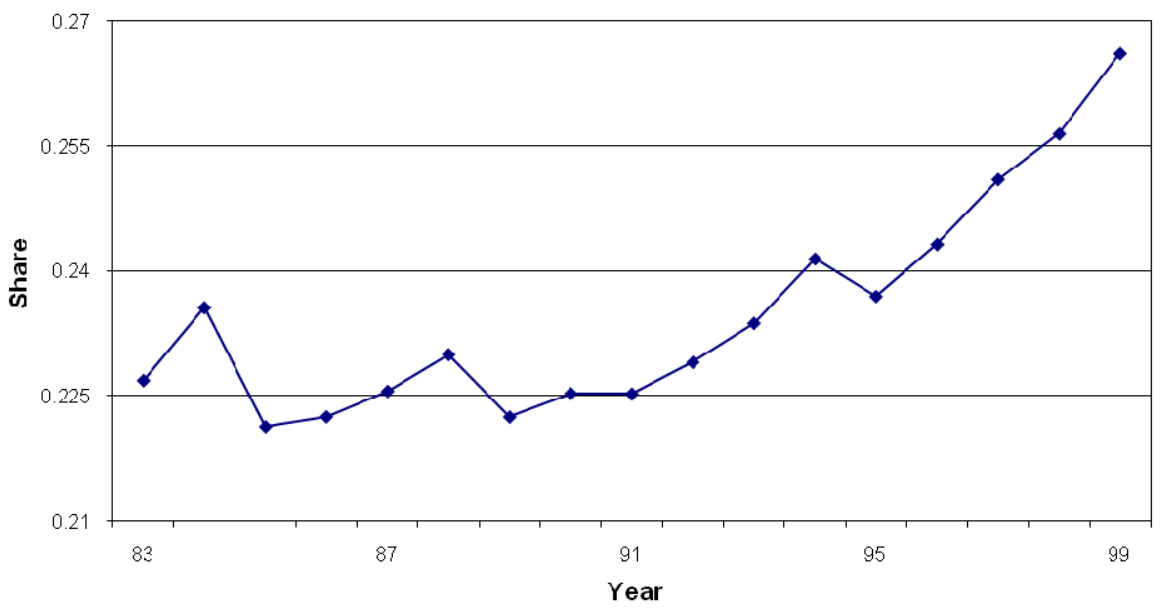


Figure 3d--Share of Other Fields,

Knowledge-Flows to Chemistry

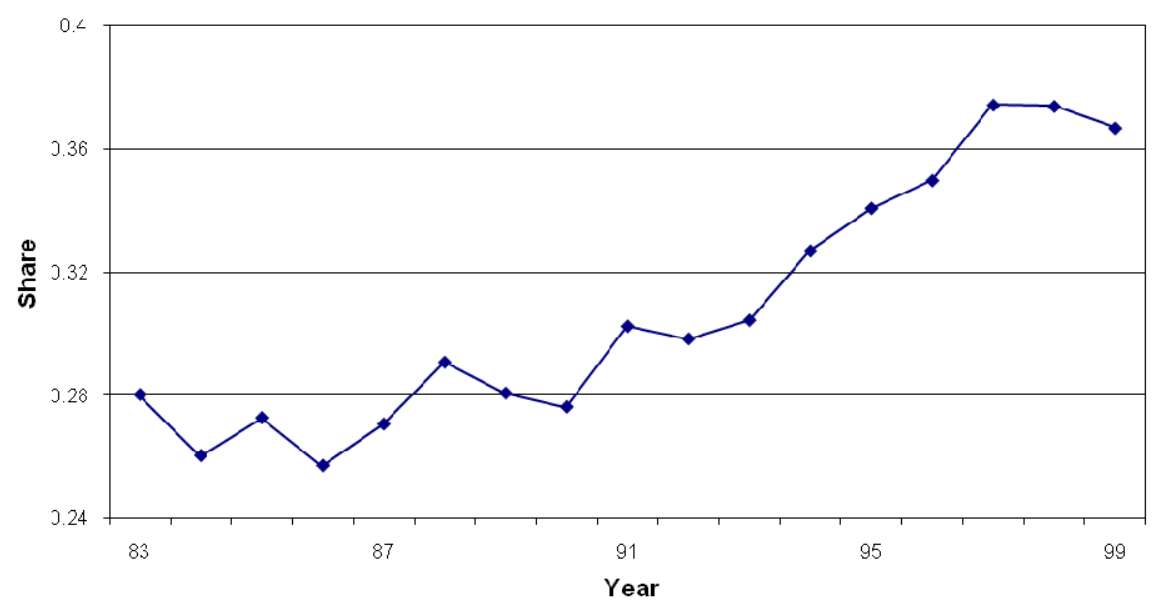

Figure 3e--Share of Other Fields,

Knowledge-Flows to Computer Science

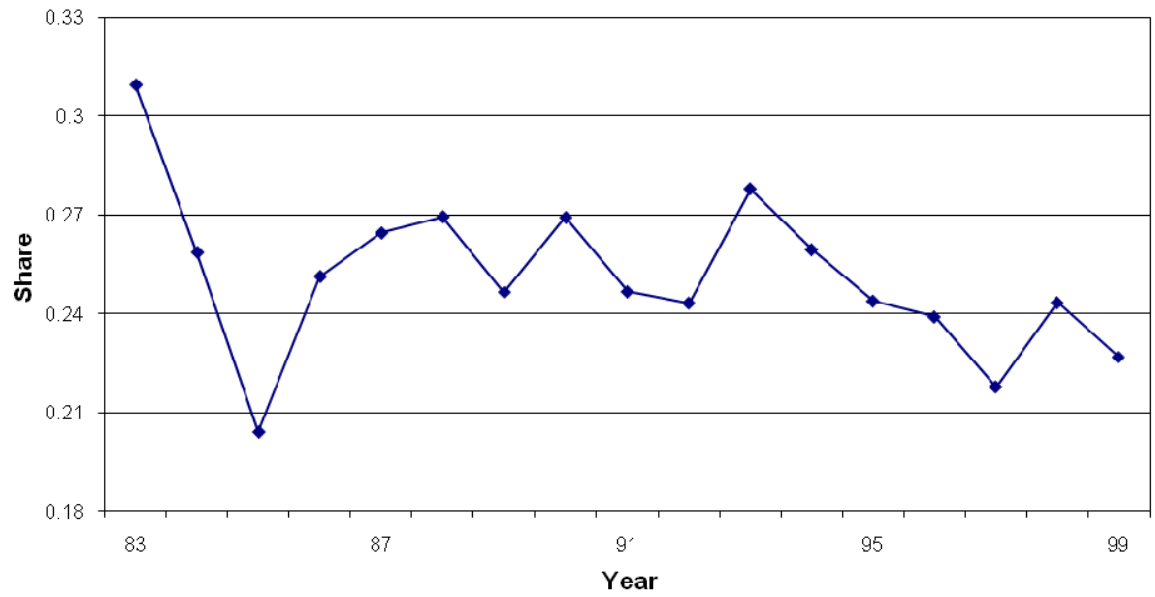

Figure 3f--Share of Other Fields,

Knowledge-Flows to Earth Sciences

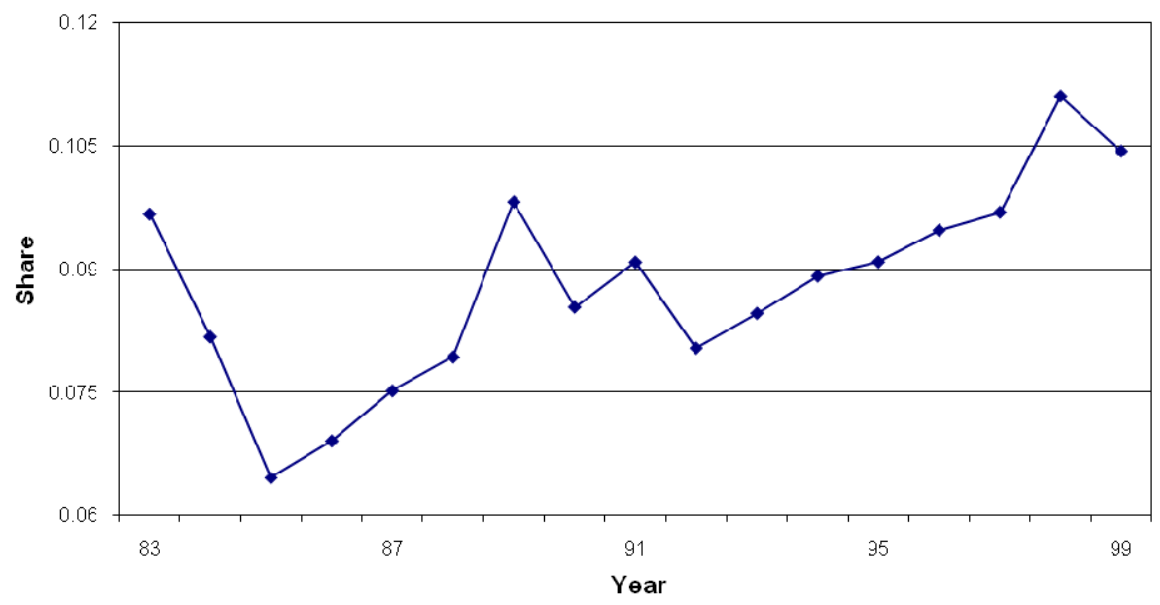


Figure $3 \mathrm{~g}$--Share of Other Fields,

Knowledge-Flows to Economics and Business

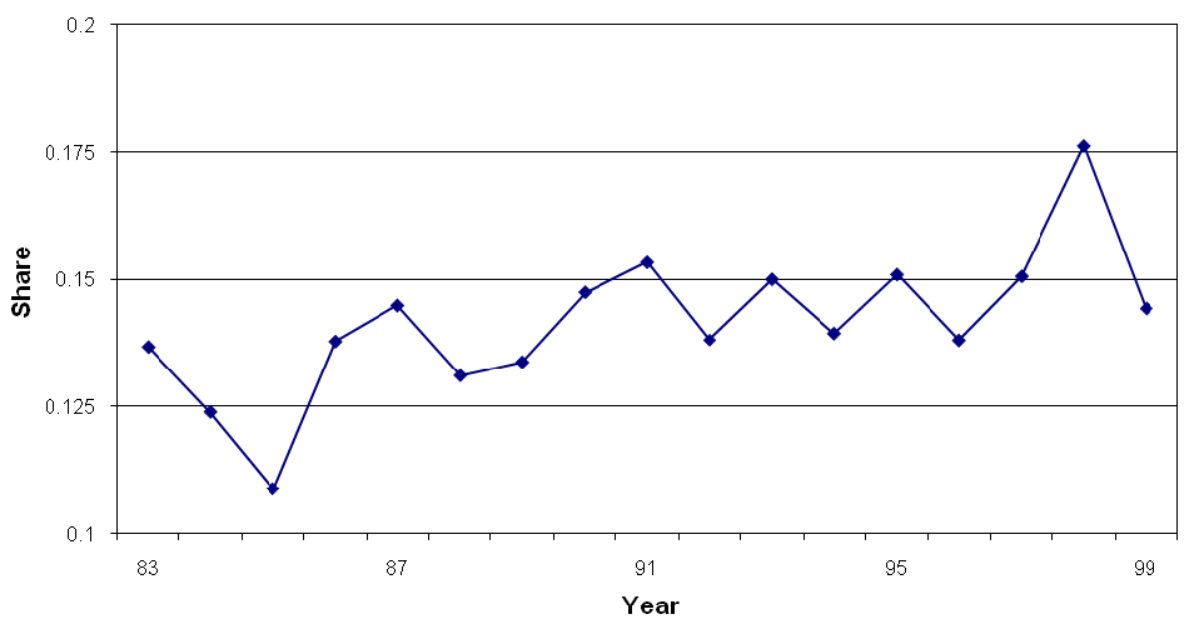

Figure 3h--Share of Other Fields,

Knowledge-Flows to Engineering

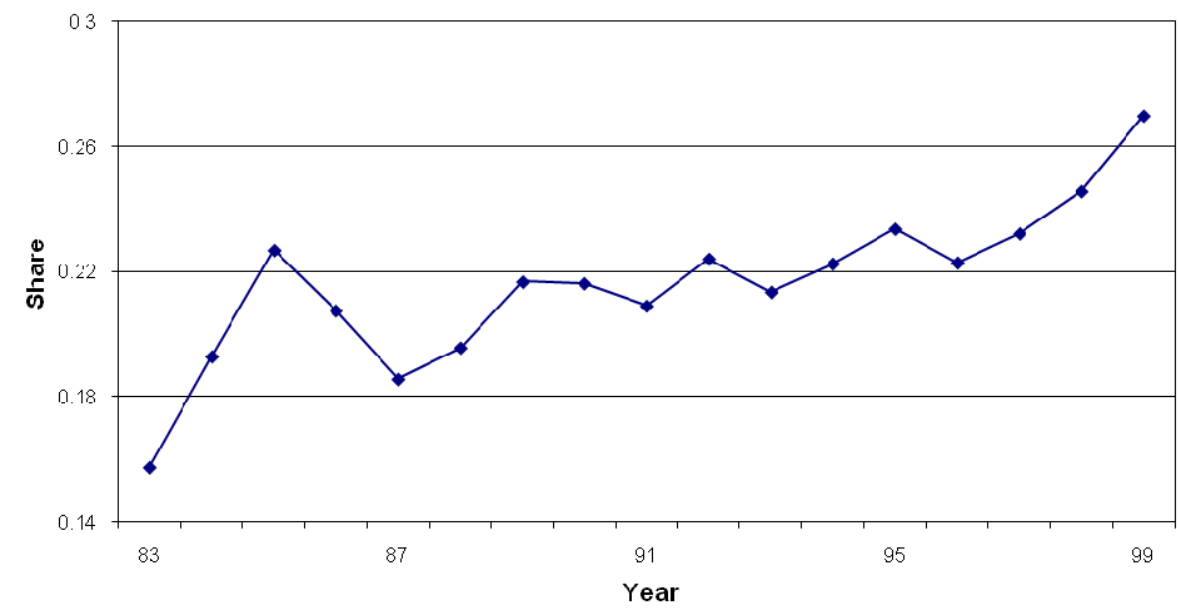

Figure 3i--Share of Other Fields,

Knowledge-Flows to Mathematics and Statistics

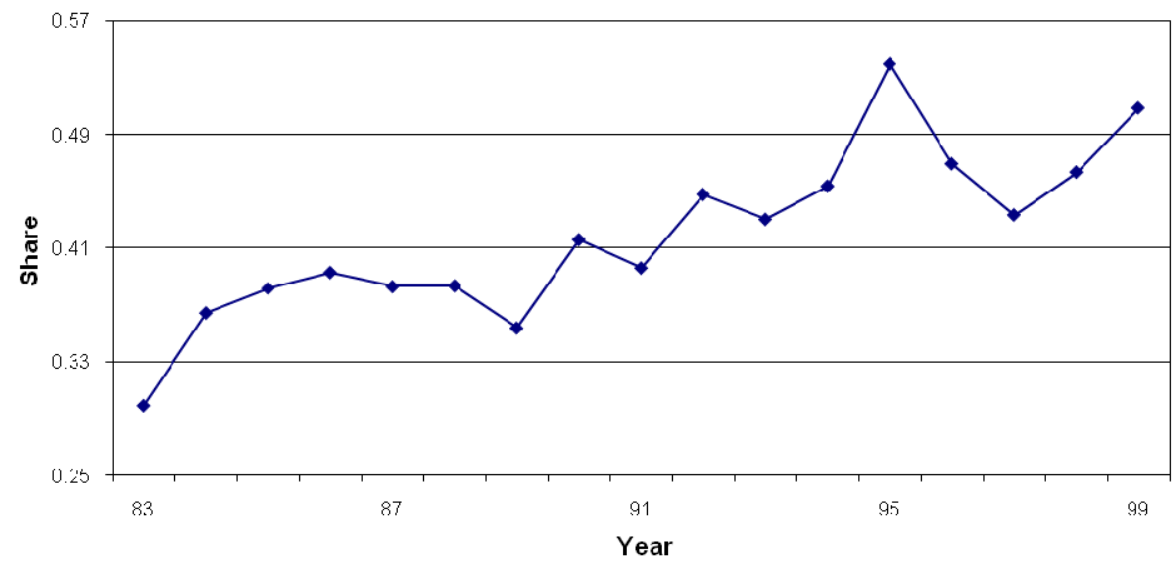


Figure 3j--Share of Other Fields,

Knowledge-Flows to Medicine

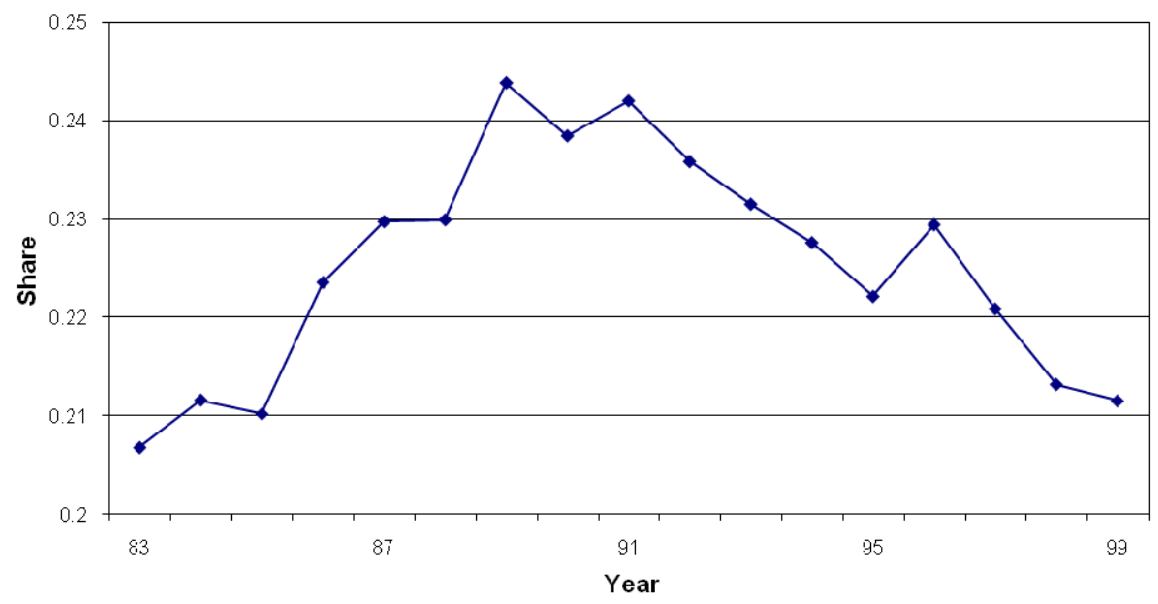

Figure $3 \mathrm{k}$--Share of Other Fields, Knowledge-Flows to Physics

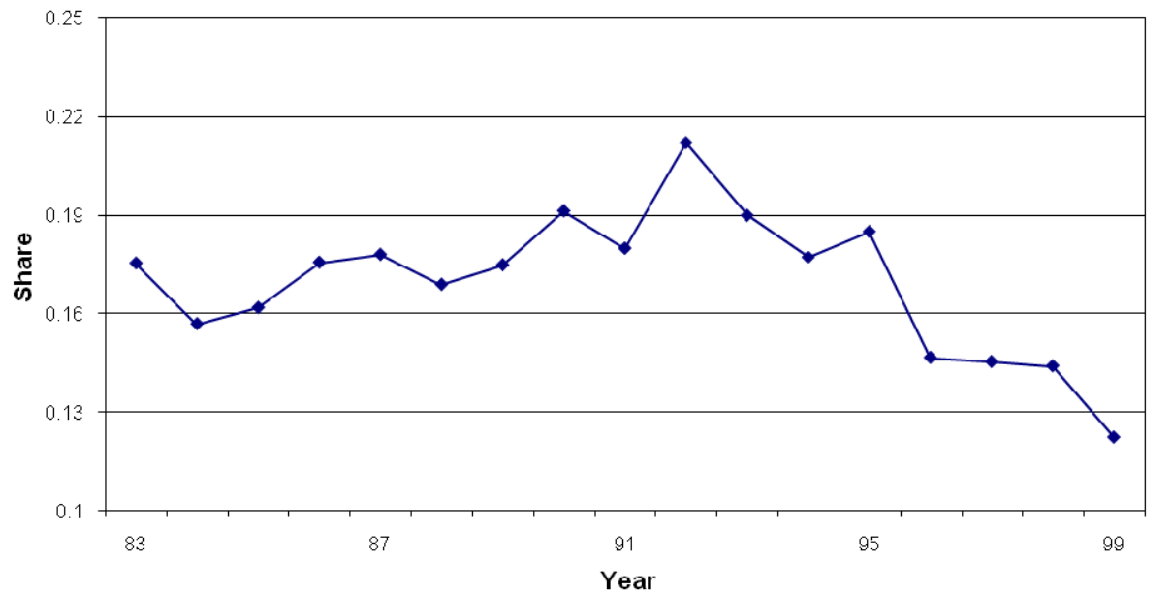

Figure 31--Share of Other Fields, Knowledge-Flows to Psychology

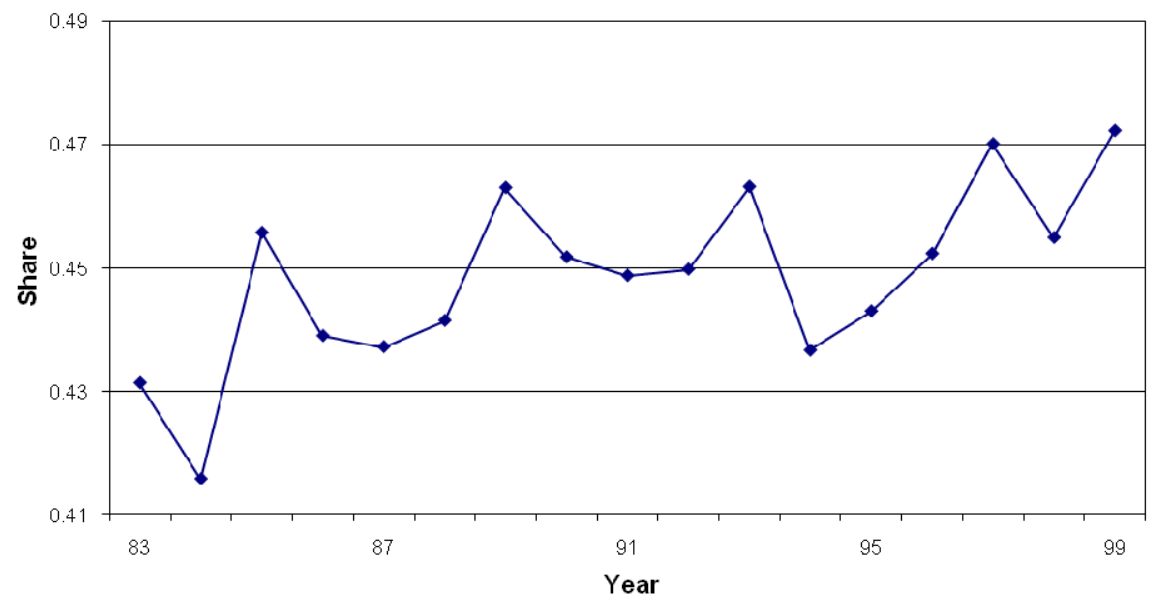


Figure 4--Share of Other Fields,

Knowledge-Flows to All Fields

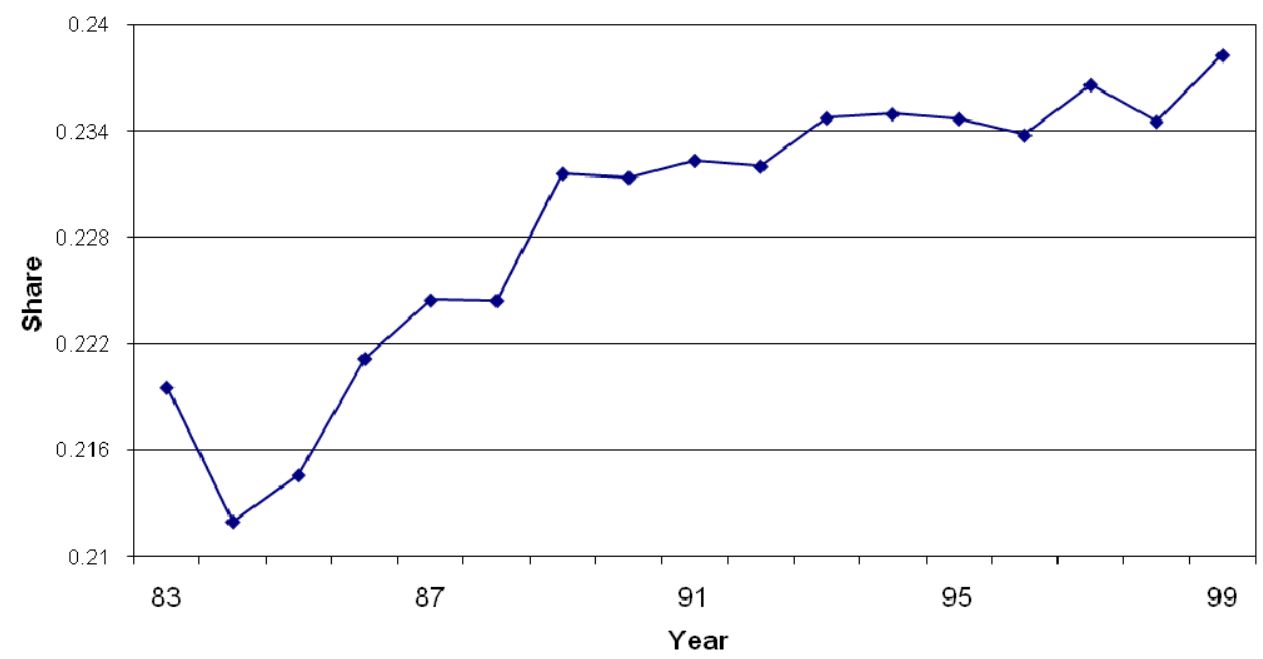

Figure 5--Share of Other Universities,

Knowledge-Flows to All Fields

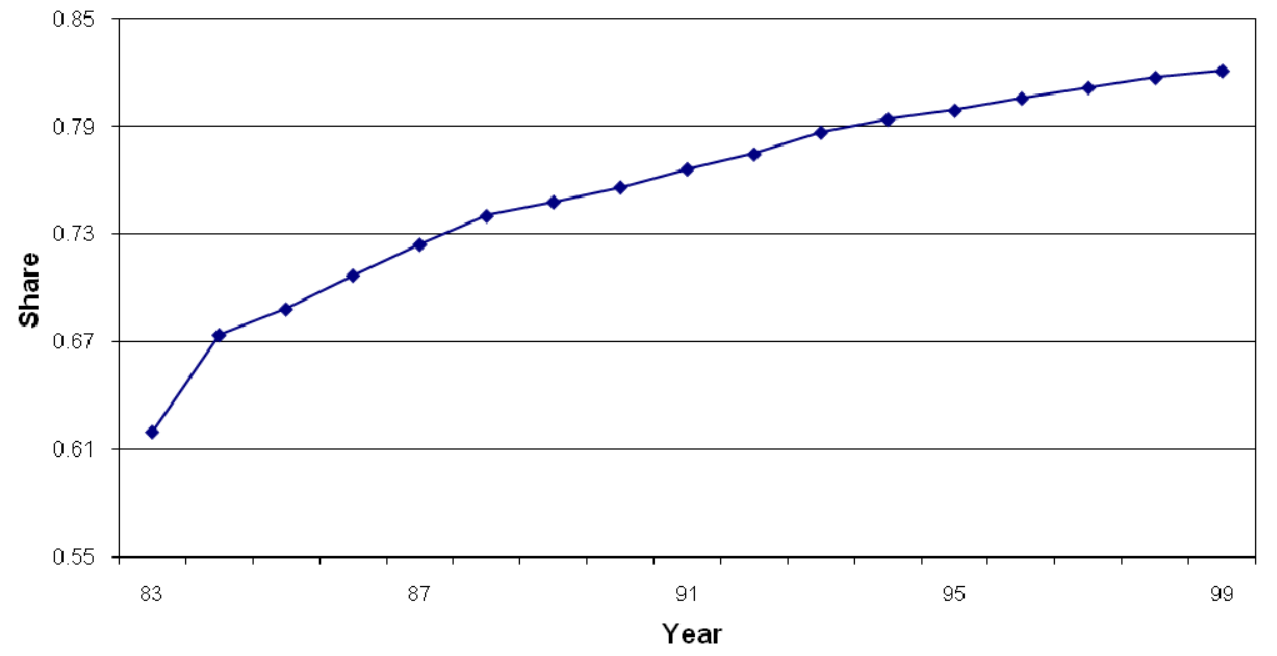



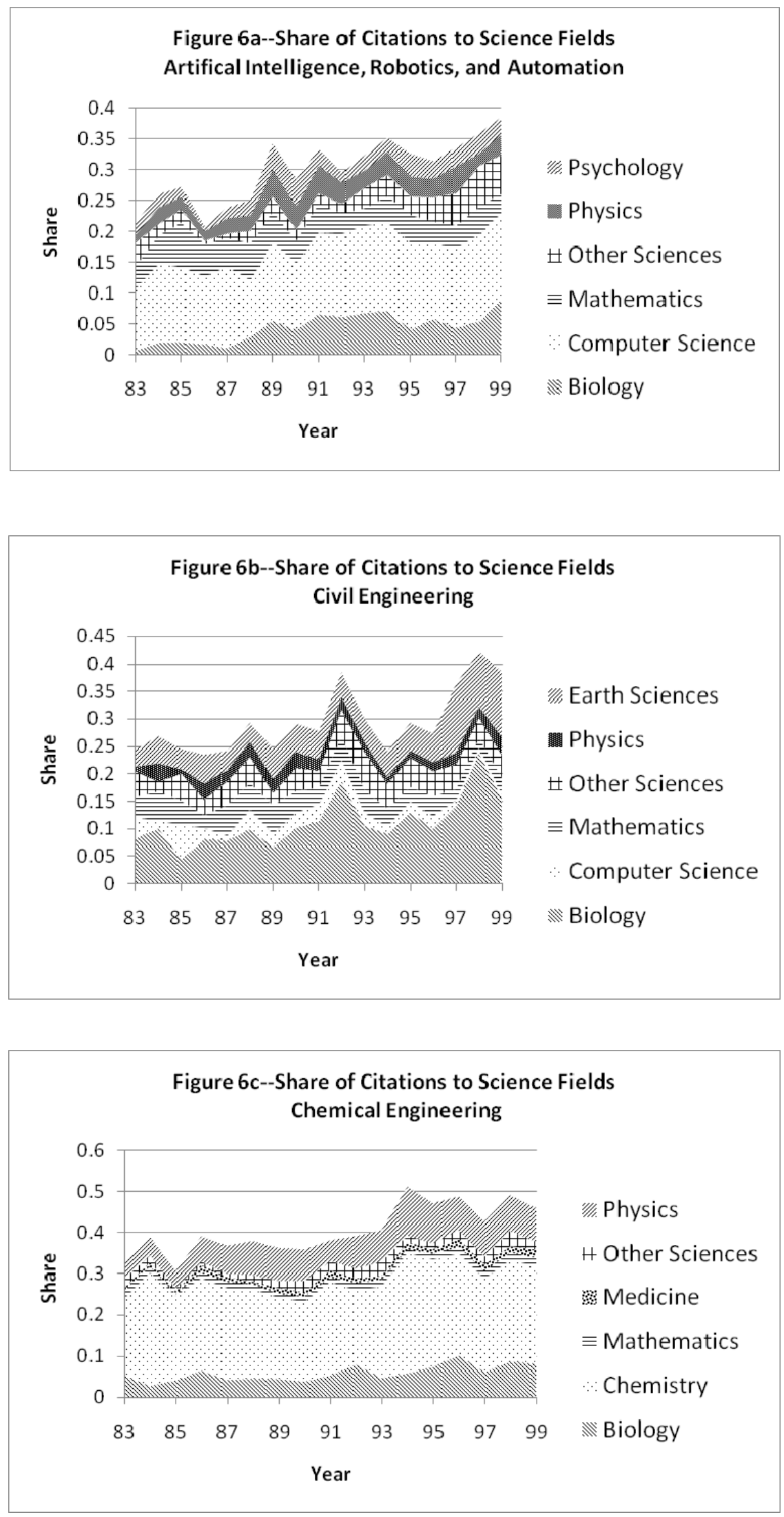

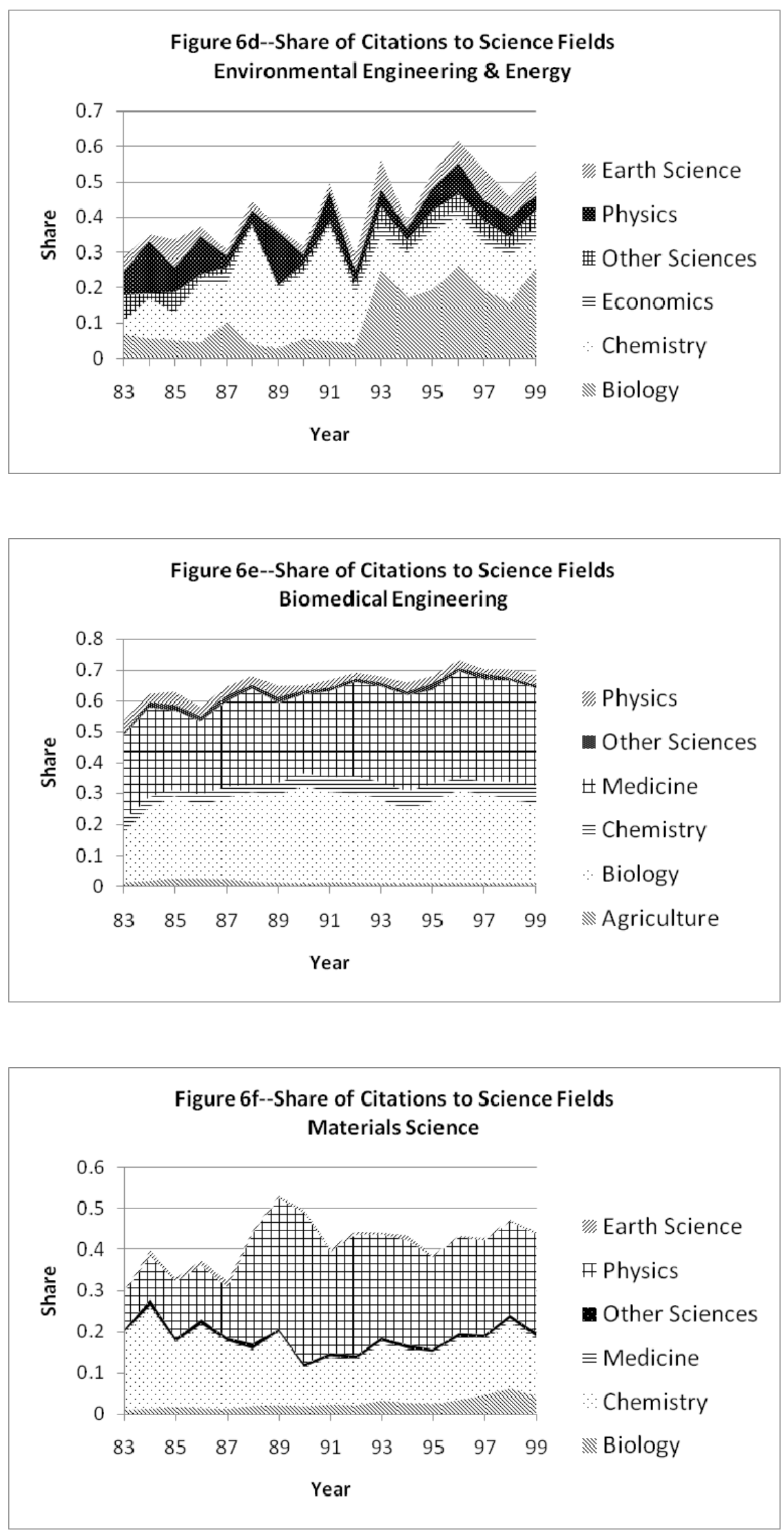

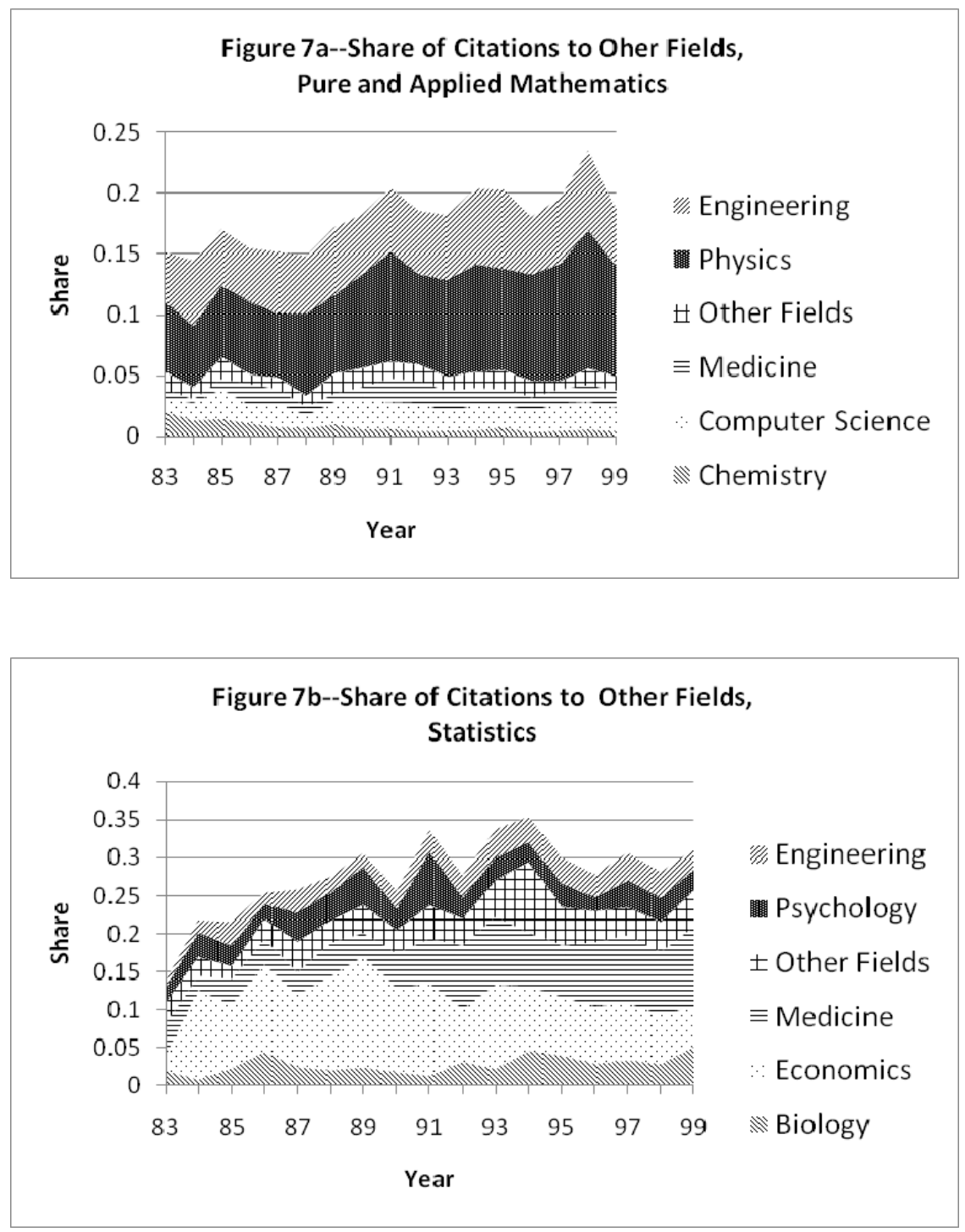


\section{Table 1}

\section{Top Cited Fields by Share in Knowledge-Flows, By Citing Field, Years 1983, 1991, and 1999}

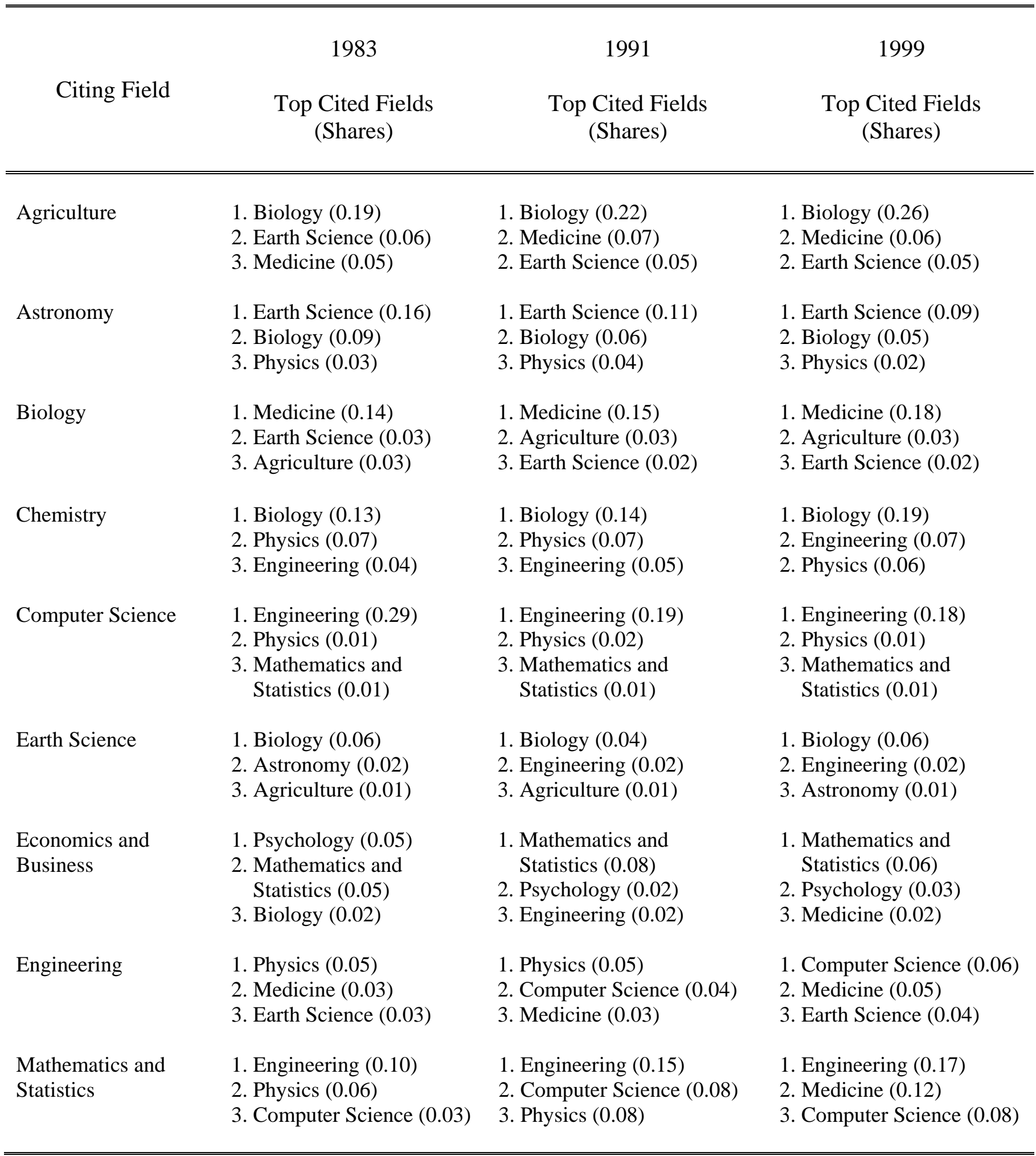




\section{Table 1}

Top Cited Fields by Share in Knowledge-Flows, By Citing Field, Years 1983, 1991, and 1999

\begin{tabular}{|c|c|c|c|}
\hline \multirow[b]{2}{*}{ Citing Field } & 1983 & 1991 & 1999 \\
\hline & $\begin{array}{c}\text { Top Cited Fields } \\
\text { (Shares) }\end{array}$ & $\begin{array}{c}\text { Top Cited Fields } \\
\text { (Shares) }\end{array}$ & $\begin{array}{c}\text { Top Cited Fields } \\
\text { (Shares) }\end{array}$ \\
\hline \multirow[t]{3}{*}{ Medicine } & 1. Biology (0.19) & 1. Biology (0.22) & 1. Biology (0.19) \\
\hline & 2. Engineering (0.01) & 2. Psychology (0.01) & 2. Engineering (0.01) \\
\hline & 3. Agriculture (0.01) & 3. Engineering (0.01) & 3. Psychology (0.01) \\
\hline \multirow[t]{3}{*}{ Physics } & 1. Engineering (0.08) & 1. Engineering (0.09) & 1. Engineering (0.06) \\
\hline & 2. Chemistry (0.03) & 2. Chemistry (0.03) & 2. Biology (0.02) \\
\hline & 3. Astronomy (0.01) & 3. Earth Science (0.02) & 3. Chemistry (0.02) \\
\hline \multirow[t]{3}{*}{ Psychology } & 1. Biology (0.22) & 1. Medicine (0.24) & 1. Medicine (0.29) \\
\hline & 2. Medicine (0.18) & 2. Biology (0.16) & 2. Biology (0.14) \\
\hline & 3. Agriculture (0.01) & $\begin{array}{l}\text { 3. Economics and } \\
\text { Business }(0.02)\end{array}$ & $\begin{array}{l}\text { 3. Economics and } \\
\text { Business }(0.02)\end{array}$ \\
\hline
\end{tabular}

Notes: Top cited fields are the top three "outside" fields with the largest share in knowledge-flows to a given science. Knowledge-flows are captured by citation-weighted R\&D stocks. See equations (4), (6)-(8) of the text for definitions of the knowledge-flows and see (9) for definitions of shares of other fields in these flows. 
Table 2

Changes in Citation Shares by Engineering Subfield, 1983-1999

Engineering Subfield

Change in Share ${ }^{\text {a }}$

$\begin{array}{ccc}\text { Same Subfield } & \text { Other } & \text { Science } \\ \text { Engineering } & \end{array}$

$\begin{array}{lccc}\text { Aeronautical Engineering } & -0.005 & 0.020 & -0.014 \\ \text { AI, Robotics, and Automatic Control } & -0.159(\mathrm{~N}) & 0.004 & 0.155(\mathrm{P}) \\ \text { Civil Engineering } & -0.161(\mathrm{~N}) & 0.022 & 0.138(\mathrm{P}) \\ \text { Chemical Engineering } & -0.126(\mathrm{~N}) & -0.013 & 0.138(\mathrm{P}) \\ \text { Environmental Engineering \& Energy } & -0.169(\mathrm{~N}) & -0.117(\mathrm{~N}) & 0.286(\mathrm{P}) \\ \text { Electrical Engineering } & 0.011 & -0.002 & -0.008 \\ \text { Engineering Mathematics } & -0.091 & 0.073 & 0.019 \\ \text { Biomedical Engineering } & -0.112(\mathrm{~N}) & -0.040 & 0.152(\mathrm{P}) \\ \text { Industrial Engineering } & 0.205(\mathrm{P}) & 0.125(\mathrm{P}) & -0.330(\mathrm{~N}) \\ \text { Mechanical Engineering } & -0.099 & 0.034 & 0.065 \\ \text { Metallurgy } & -0.181(\mathrm{~N}) & 0.202(\mathrm{P}) & -0.022 \\ \text { Materials Science } & -0.173(\mathrm{~N}) & 0.021 & 0.152(\mathrm{P}) \\ \text { Nuclear Engineering } & -0.101(\mathrm{~N}) & 0.034 & 0.067\end{array}$

Notes: ${ }^{a}$ Citation share in yeart is CiteShare ${ }_{t}^{j}=$ Citations $_{t}^{j} / \sum_{i}$ Citations $_{t}^{i}$, where $i, j=$ engineering subfield, other engineering, and science. Change in the citation share is $\Delta$ CiteShare $_{99,83}^{j}=$ CiteShare $_{99}^{j}-$ CiteShare $_{83}^{j}$. Symbol (N) indicates that the share decreases by at least 0.1 and $(\mathrm{P})$ indicates that the share increases by at least 0.1 . 
Table 3

Descriptive Statistics from a Panel of U.S. Universities, 1983-1999

For a Study of University Research Productivity

(Logarithms in Parentheses)

\begin{tabular}{|c|c|c|}
\hline Variable & $\begin{array}{c}\text { Mean } \\
\text { (in Logarithms) }\end{array}$ & $\begin{array}{c}\text { St. Dev. } \\
\text { (in Logarithms) }\end{array}$ \\
\hline Papers ${ }^{\text {a }}$ & $\begin{array}{l}196.5 \\
(4.58)\end{array}$ & $\begin{array}{l}345.0 \\
(1.19)\end{array}$ \\
\hline Citations Received ${ }^{\mathrm{b}}$ & $\begin{array}{l}440.1 \\
(2.26)\end{array}$ & $\begin{array}{l}1168.7 \\
(5.30)\end{array}$ \\
\hline Knowledge-Flows (in mill. of ’92 \$) & & \\
\hline Total & $\begin{array}{l}676.8 \\
(5.19)\end{array}$ & $\begin{array}{c}1550.3 \\
(1.85)\end{array}$ \\
\hline Same Field ${ }^{\mathrm{c}}$ & $\begin{array}{l}519.0 \\
(4.88)\end{array}$ & $\begin{array}{l}1169.4 \\
(1.92)\end{array}$ \\
\hline Other Fields ${ }^{c}$ & $\begin{array}{l}157.8 \\
(3.57)\end{array}$ & $\begin{array}{l}409.3 \\
(2.18)\end{array}$ \\
\hline Same University ${ }^{\mathrm{d}}$ & $\begin{array}{l}143.8 \\
(3.53)\end{array}$ & $\begin{array}{l}303.3 \\
(2.12)\end{array}$ \\
\hline Other Universities $^{\mathrm{d}}$ & $\begin{array}{l}533.0 \\
(4.89)\end{array}$ & $\begin{array}{c}1269.5 \\
(1.93)\end{array}$ \\
\hline R\&D Stock (in Millions of '92 \$) ${ }^{e}$ & $\begin{array}{c}81.9 \\
(3.31)\end{array}$ & $\begin{array}{l}134.7 \\
(1.98)\end{array}$ \\
\hline
\end{tabular}

Notes: Data are a three-dimensional panel of fields, universities of science and years. The number of observations is $\mathrm{N}=11,220$ before exclusions due to missing values. Arithmetic means and standard deviations appear above while logarithmic means and standard deviations appear below in parentheses. Knowledge-flows are citation-weighted R\&D stocks. See equations (4), (6)-(8) of the text for definitions of the flows. ${ }^{\text {a }}$ Papers are fractional counts of articles written in a university, field and year, where fractions are adjusted for shared publication with other universities. ${ }^{\mathrm{b}}$ Citations received are all citations received from other universities during the first five years of a paper including the publication year, and are fractionalized in the same way as papers. ' Same field knowledge-flows occur when citing and cited fields are the same, while other field flows occur when the two fields differ. ${ }^{\mathrm{d}}$ Same university knowledge-flows occur when citing and cited universities are the same, while other university flows occur when the two universities differ. ${ }^{\mathrm{e}} \mathrm{R} \& \mathrm{D}$ stock is the sum of depreciated flows of R\&D over the previous eight years, expressed in 1992 dollars and assuming a rate of depreciation of 15 percent. 
Table 4-Scientific Papers of U.S. Universities:

Knowledge-Flows Within and Between Universities, 1983-1999

(Robust, Clustered Standard Errors in Parentheses)

\begin{tabular}{|c|c|c|c|c|c|c|}
\hline \multirow[t]{2}{*}{ Variable or Statistic } & \multicolumn{3}{|c|}{ Log (Papers) } & \multicolumn{3}{|c|}{ Log (Citations Received) } \\
\hline & Eq. 4.1 & Eq. 4.2 & Eq. 4.3 & Eq. 4.4 & Eq. 4.5 & Eq. 4.6 \\
\hline Time Period & \multicolumn{3}{|c|}{ 1983-1999 } & \multicolumn{3}{|c|}{ 1983-1995 } \\
\hline Log (Stock of Total R\&D) & $\begin{array}{c}0.169 * * \\
(0.023)\end{array}$ & $\begin{array}{c}0.186^{* *} \\
(0.025)\end{array}$ & $\begin{array}{c}0.187 * * \\
(0.024)\end{array}$ & $\begin{array}{c}0.172 * * \\
(0.032)\end{array}$ & $\begin{array}{c}0.203^{* *} \\
(0.032)\end{array}$ & $\begin{array}{r}0.202 * * \\
(0.030)\end{array}$ \\
\hline Log (Knowledge-Flow) & $\begin{array}{c}0.400 * * \\
(0.040)\end{array}$ & & & $\begin{array}{l}0.478^{* *} \\
(0.051)\end{array}$ & & \\
\hline $\begin{array}{l}\text { Log (Knowledge-Flow, Same } \\
\text { University) }\end{array}$ & & $\begin{array}{c}0.072^{* *} \\
(0.019)\end{array}$ & $\begin{array}{c}0.080^{* *} \\
(0.017)\end{array}$ & & $\begin{array}{l}0.075^{* *} \\
(0.022)\end{array}$ & $\begin{array}{c}0.085^{* *} \\
(0.020)\end{array}$ \\
\hline $\mathrm{I}($ Year in the $1990 \mathrm{~s}) \times$ & & & $-0.045^{* *}$ & & & $-0.077 * *$ \\
\hline $\begin{array}{l}\text { Log(Knowledge-Flow, Same } \\
\text { University }\end{array}$ & & & $(0.016)$ & & & $(0.019)$ \\
\hline Log (Knowledge-Flow, Other & & $0.286^{* *}$ & $0.259 * *$ & & $0.347 * *$ & $0.321 * *$ \\
\hline Universities) & & $(0.024)$ & $(0.024)$ & & $(0.035)$ & $(0.031)$ \\
\hline I(Year in the 1990s) $\times$ & & & $0.130 * *$ & & & $0.212 * *$ \\
\hline Log(Knowledge-Flow, Other & & & $(0.020)$ & & & $(0.023)$ \\
\hline Universities & & & & & & \\
\hline No. of Obs. & 9856 & 9856 & 9856 & 7534 & 7534 & 7534 \\
\hline R-squared & 0.920 & 0.917 & 0.920 & 0.921 & 0.919 & 0.923 \\
\hline Root Mean Squared Error & 0.315 & 0.320 & 0.313 & 0.453 & 0.457 & 0.447 \\
\hline
\end{tabular}

Notes: Data are a panel of fields, universities, and years. All equations include fixed effects for university, field, and year. Standard errors are adjusted for clustering by university. Method is OLS. Knowledge-flows are sums of citation-weighted R\&D stocks as defined in (4), (6)-(8) of the text. ${ }^{* *}$ Coefficient is significantly different from zero at the one percent level. 
Table 5-Scientific Papers of U.S. Universities:

Knowledge-Flows Within and Between Fields, 1983-1999

(Robust, Clustered Standard Errors in Parentheses)

Variable or Statistic

Log (Papers)

Log (Citations Received)

$\begin{array}{llllll}\text { Eq. } 5.1 & \text { Eq. } 5.2 & \text { Eq. } 5.3 & \text { Eq. } 5.4 & \text { Eq. } 5.5 & \text { Eq. } 5.6\end{array}$

Time Period

1983-1999

1983-1995

Log (Stock of Total R\&D)

$0.174 * *$

$0.205^{* *}$

$0.164 * *$

$0.178^{* *}$

$0.228 * *$

$0.164 * *$

Log (Knowledge-Flow, Same Field)

(0.023)

(0.025)

(0.021)

(0.032)

$(0.031)$

(0.030)

$0.296 * *$

$0.275^{* *}$

$0.370 * *$

$0.349 * *$

(0.034)

(0.033)

(0.048)

(0.046)

$0.068 * *$

$0.107 * *$

(0.014)

$(0.020)$

Same Field)

Log (Knowledge-Flow, Other Fields)

$0.080 * *$

$0.086^{* *}$

$0.072 * *$

$0.081 * *$

(0.011)

$(0.010)$

(0.013)

(0.012)

0.014

0.014

Other Fields)

(0.014)

Log (Knowledge-Flow, Same Field/Same

University)

Log (Knowledge-Flow, Same Field/Other

Universities)

Log (Knowledge-Flow, Other Fields/Same

University)

Log (Knowledge-Flow, Other Fields/Other

Universities)

$0.036^{*}$

$(0.018)$

(0.015)

$0.211^{* *}$

(0.024)

$0.038 * *$

(0.005)

0.037 **

(0.008)

$0.036^{*}$

(0.018)

$0.267 * *$

(0.029)

0.031 **

(0.007)

$0.037 * *$

(0.011)

No. of Obs.

9856

0.919

9856

0.921

9856

7534

0.920

7534

7534

0.315

0.320

0.309

0.456

0.918

0.923

Root Mean Squared Error

Notes: Data are a panel of fields, universities, and years. All equations include fixed effects for university, field, and year. Standard errors are adjusted for clustering by university. Method is OLS. Knowledge-flows are sums of citation-weighted R\&D stocks as defined in (4), (6)-(8) of the text. ${ }^{* *}$ Coefficient is significantly different from zero at the one percent level. * Coefficient is significantly different from zero at the five percent level. 
Table 6

Matching of Citing Fields to "Hot" Fields

Citing Field

“Hot” Fields

Agriculture

Astronomy

Biology, Medicine

Biology

$<<$ None $>>$

Chemistry

Computer Science

Medicine

Biology, Engineering

$<<$ None $>>$

Economics and Business

Earth Sciences

Engineering ,Mathematics and Statistics

Engineering

Mathematics and Statistics

$<<$ None $>>$

Biology, Computer Science, Earth Sciences, Medicine

Computer Science, Engineering, Medicine

Medicine

Physics

$<<$ None $>>$

$<<$ None $>>$

Psychology

Medicine

Notes: "Hot" fields are other fields whose share in knowledge-flows increases by at least one percent between 1983 and 1999. Citing fields with no "hot" fields are those where the share of knowledge-flows from other fields declines. 


\section{Table 7-Scientific Papers of U.S. Universities: Citation-Weighted R\&D, "Hot” and “Cold” Fields, 1983-1999 (Robust, Clustered Standard Errors in Parentheses)}

\begin{tabular}{|c|c|c|c|c|c|c|}
\hline \multirow[b]{2}{*}{ Variable or Statistic } & \multicolumn{3}{|c|}{ Log (Papers) } & \multicolumn{3}{|c|}{ Log (Citations Received) } \\
\hline & Eq. 7.1 & Eq. 7.2 & Eq. 7.3 & Eq. 7.4 & Eq. 7.5 & Eq. 7.6 \\
\hline Time Period & \multicolumn{3}{|c|}{ 1983-1999 } & \multicolumn{3}{|c|}{ 1983-1995 } \\
\hline Log (Stock of Total R\&D) & $\begin{array}{l}0.175^{* *} \\
(0.023)\end{array}$ & $\begin{array}{c}0.167 * * \\
(0.021)\end{array}$ & $\begin{array}{c}0.160 * * \\
(0.020)\end{array}$ & $\begin{array}{c}0.181^{* *} \\
(0.032)\end{array}$ & $\begin{array}{l}0.175^{* *} \\
(0.030)\end{array}$ & $\begin{array}{l}0.161^{* *} \\
(0.028)\end{array}$ \\
\hline Log (Knowledge-Flow, Same Field) & $\begin{array}{l}0.318^{* *} \\
(0.035)\end{array}$ & $\begin{array}{c}0.308^{* *} \\
(0.033)\end{array}$ & $\begin{array}{c}0.289 * * \\
(0.031)\end{array}$ & $\begin{array}{c}0.387 * * \\
(0.048)\end{array}$ & $\begin{array}{c}0.376 * * \\
(0.046)\end{array}$ & $\begin{array}{c}0.345^{* *} \\
(0.043)\end{array}$ \\
\hline $\begin{array}{l}\text { I(Year in 1990s) } \times \text { Log (Knowledge- } \\
\text { Flow, Same Field) }\end{array}$ & & & $\begin{array}{c}0.043^{* *} \\
(0.009)\end{array}$ & & & $\begin{array}{c}0.148^{* *} \\
(0.017)\end{array}$ \\
\hline Log (Knowledge-Flow, “Hot” Fields) & $\begin{array}{c}0.020^{\mathrm{a}} * * \\
(0.006)\end{array}$ & $\begin{array}{c}0.054^{\mathrm{a} * *} \\
(0.010)\end{array}$ & $\begin{array}{c}0.056^{\mathrm{a}} * * \\
(0.010)\end{array}$ & $\begin{array}{c}0.045^{\mathrm{c}} * * \\
(0.008)\end{array}$ & $\begin{array}{c}0.091^{\mathrm{C}} * * \\
(0.013)\end{array}$ & $\begin{array}{c}0.115^{\mathrm{d}} * * \\
(0.015)\end{array}$ \\
\hline I(“Hot” Fields=0)× Log(Knowledge- & & $-0.061^{* *}$ & $-0.054 * *$ & & $-0.078^{* *}$ & $-0.088^{* *}$ \\
\hline $\begin{array}{l}\text { I(Year in 1990s)× Log (Knowledge- } \\
\text { Flow, "Hot" Fields) }\end{array}$ & & & $\begin{array}{c}0.00019^{\mathrm{b}} * * \\
(0.00004)\end{array}$ & & & $\begin{array}{c}-0.012^{\mathrm{b} * *} \\
(0.003)\end{array}$ \\
\hline $\begin{array}{l}\text { Log (Knowledge-Flow, “Cold” } \\
\text { Fields) }\end{array}$ & $\begin{array}{c}0.032^{\mathrm{a}} * * \\
(0.006)\end{array}$ & $\begin{array}{c}0.071^{\mathrm{a} * *} \\
(0.009)\end{array}$ & $\begin{array}{c}0.068^{\mathrm{a}} * * \\
(0.008)\end{array}$ & $\begin{array}{c}0.022^{\mathrm{c}} * * \\
(0.008)\end{array}$ & $\begin{array}{c}0.053^{\mathrm{c}} * * \\
(0.011)\end{array}$ & $\begin{array}{c}0.061^{\mathrm{d}} * * \\
(0.011)\end{array}$ \\
\hline I(“Cold” Fields=0)× Log(Knowledge- & & $-0.076^{* *}$ & $-0.063 * *$ & & $-0.057 * *$ & $-0.046^{* *}$ \\
\hline Flow, “Cold” Fields) & & $(0.011)$ & $(0.011)$ & & $(0.016)$ & $(0.016$ \\
\hline I(Year in 1990s)× Log (Knowledge- & & & $0.00021^{\mathrm{b}} * *$ & & & $-0.031^{\mathrm{b} * *}$ \\
\hline Flow, “Cold” Fields) & & & $(0.00004)$ & & & $(0.011)$ \\
\hline No. of Obs. & 9856 & 9856 & 9856 & 7534 & 7534 & 7534 \\
\hline R-squared & 0.918 & 0.921 & 0.924 & 0.920 & 0.922 & 0.925 \\
\hline Root Mean Squared Error & 0.318 & 0.312 & 0.306 & 0.455 & 0.451 & 0.442 \\
\hline
\end{tabular}

Notes: Data are a panel of fields, universities, and years. All equations include fixed effects for university, field, and year. Standard errors are adjusted for clustering by university. Method is OLS. Knowledge-flows are sums of citation-weighted R\&D stocks as defined in (4), (6)-(8) of the text. **Coefficient is significantly different from zero at the one percent level. a Coefficients of "hot" and "cold" fields are not significantly different at the five percent level. " Coefficients of "hot" and "cold" interactions with the 1990s are not significantly different at the five percent level. " Coefficients of "hot" and "cold" fields are significantly different at the five percent level. " Coefficients of "hot" and "cold" fields are significantly different at the one percent level. 


\section{Table 8-Scientific Papers of Top 200 U.S. R\&D Firms: Knowledge-Flows within and between Fields, 1983-1999 (Robust, Clustered Standard Errors in Parentheses)}

Variable or Statistic

Log (Papers)

$\begin{array}{lllll}\text { Eq. } 8.1 & \text { Eq. } 8.2 & \text { Eq. } 8.3 & \text { Eq. } 8.4 & \text { Eq. } 8.5\end{array}$

Time Period 1983-1999

Log (Stock of Basic Research)

$\begin{array}{cc}0.055^{* *} & 0.057 * * \\ (0.020) & (0.020) \\ 0.235^{* *} & 0.206^{* *} \\ (0.013) & (0.014) \\ & 0.049 * * \\ & (0.014) \\ 0.094^{* *} & 0.090^{* *} \\ (0.010) & (0.012) \\ & 0.006 \\ & (0.010)\end{array}$

$\begin{array}{ccc}0.055^{* *} & 0.051^{* *} & 0.051^{* *} \\ (0.018) & (0.017) & (0.017) \\ 0.224 * * & 0.204^{* *} & 0.179 * * \\ (0.012) & (0.010) & (0.011) \\ & & 0.040^{* *} \\ & & (0.013)\end{array}$

I(Year in 1990

Log (Knowledge-Flow, Other Fields)

$(0.010)$

$\mathrm{I}($ Year in 1990s) $\times$ Log (Knowledge-Flow, Other Fields)

Log (Knowledge-Flow, “Hot” Fields)

I(“Hot” Other Fields=0) $\times \log ($ Knowledge-

Flow, "Hot” Fields)

I(Year in 1990s) × Log (Citation-Weighted

R\&D, "Hot” Fields)

Log (Citation-Weighted R\&D, “Cold” Fields)

I(“Cold” Other Fields=0)× Log(Knowledge-

Flow, "Cold” Fields)

$\mathrm{I}($ Year in 1990s) $\times \mathrm{I}($ Year in 1990s $) \times$ Log

(Citation-Weighted R\&D, “Cold” Fields)

$\begin{array}{ccc}0.044^{\mathrm{a} * *} & 0.136^{\mathrm{b} * *} & 0.138^{\mathrm{c} * *} \\ (0.007) & (0.017) & (0.020) \\ & -0.116^{* *} & -0.115^{* *} \\ & (0.018) & (0.019) \\ & & -0.005^{\mathrm{d}} \\ & & (0.006) \\ 0.088^{\mathrm{a} * *} & 0.190^{\mathrm{b}} * * & 0.207^{\mathrm{c} * *} \\ (0.009) & (0.020) & (0.022) \\ & -0.148^{* *} & -0.149^{* *} \\ & (0.019) & (0.020) \\ & & -0.026^{\mathrm{d}} \\ & & (0.009) \\ 5615 & 5615 & 5615 \\ 0.703 & 0.727 & 0.728 \\ 0.848 & 0.814 & 0.813\end{array}$

No. of Obs.

$\begin{array}{ll}5615 & 5615 \\ 0.694 & 0.696 \\ 0.861 & 0.858\end{array}$

0.848

0.727

0.813

Notes: Data are a panel of firms, fields, and years. All equations include fixed effects for firm, field, and year. Standard errors are adjusted for clustering by firm. Method is OLS. Knowledge-flows are sums of citation-weighted R\&D stocks as defined in (4), (6)-(8) of the text, but adapted to data on firms. ${ }^{* *}$ Coefficient is significantly different from zero at the one percent level of significance. " The coefficients of "hot" and "cold" fields are significantly different at the one percent level. " The coefficients of "hot" and "cold" fields are not significantly different at the five percent level. " The coefficients of "hot" and "cold" fields are significantly different at the five percent level. ${ }^{\mathrm{d}}$ Coefficients of the "hot" and "cold" interactions with the 1990s are not significantly different at the five percent level. 